\title{
THE OUTCOME OF COMPETITIVE EQUILIBRIUM RULES IN BUYER- SELLER MARKETS WHEN THE AGENTS PLAY STRATEGICALLY ${ }^{1}$
}

\author{
by \\ David Pérez-Castrillo ${ }^{2}$ and Marilda Sotomayor ${ }^{3}$
}

\begin{abstract}
We analyze the two-stage games induced by competitive equilibrium rules for the buyer-seller market of Shapley and Shubik (1972). In these procedures, first sellers and then buyers report their valuation and the outcome is determined by a competitive equilibrium outcome for the market reported by the agents. We provide results concerning buyers and sellers' equilibrium strategies. In particular, our results point out that, by playing first, sellers are able to instigate an outcome that corresponds to the sellers' optimal competitive equilibrium allocation for the true market.
\end{abstract}

Key words: assignment game, competitive price, optimal matching, competitive rule JEL numbers: C78, D78

\footnotetext{
${ }^{1}$ We thank three reviewers and an Associate Editor for very helpful comments. Marilda Sotomayor is a research fellow at CNPq-Brazil. David Pérez-Castrillo is a fellow of MOVE and CESIfo. He acknowledges financial support from the Ministerio de Ciencia y Tecnología (ECO2015-63679-P), Generalitat de Catalunya (2014SGR-142), the Severo Ochoa Programme for Centres of Excellence in R\&D (SEV-2015-0563) and ICREA Academia.

${ }^{2}$ Universitat Autònoma de Barcelona and Barcelona GSE; Dept. Economía e Hist. Económica; Edificio B; 08193 Bellaterra - Barcelona; Spain. Email: david.perez@uab.es.

${ }^{3}$ University of São Paulo; Dep de Economia; Av. Prof. Luciano Gualberto, 908; Cidade Universitária, 5508-900, São Paulo, SP, Brazil.
} 


\section{INTRODUCTION}

We analyze a one-to-one buyer-seller market where a set of possibly heterogeneous sellers and a set of possibly heterogeneous buyers meet. Each seller owns one indivisible object, for which he has a certain valuation. Each buyer places a monetary value on each of the objects and she is interested in acquiring at most one of them. This market is a version of the assignment game, introduced in Shapley and Shubik (1972). While we refer to the model as the buyer-seller market, many other markets enter into our framework, including the labor markets in which workers sell their services for salaries.

For the buyer-seller market an outcome consists of a matching function that states who buys from whom (and which agent does not sell or does not buy), and a vector of prices for the objects. Gale (1960) proposes the competitive equilibrium as a reasonable solution concept for this market. In a competitive equilibrium, the demand of every buyer is satisfied (that is, each buyer receives an object that maximizes her surplus, given the prices, whenever this surplus is non-negative), the price of each unsold object is its seller's reservation price, and no two buyers are assigned the same object. Gale (1960) also proves the existence of competitive equilibrium outcomes. Shapley and Shubik (1972) show that a competitive equilibrium matching is an optimal matching, in the sense that it maximizes the sum of the gains of the whole set of agents. They also prove that the set of competitive equilibrium prices forms a complete lattice whose extreme points are the minimum and the maximum equilibrium prices, which are called buyer-optimal and seller-optimal competitive prices, respectively. ${ }^{4}$ Finally, it is possible to define a cooperative model for the buyer-seller market and the previous results also apply to the cooperative model because the core coincides with the set of competitive equilibrium payoffs (Shapley and Shubik, 1972).

Competitive equilibria provide efficient, stable, and envy-free allocations. However, they may be very difficult to obtain through decentralized processes with contracts, bids, offers, and counter offers. In this paper we explore the idea of using competitive equilibria as the basis for centralized mechanisms that set the prices for the objects and allocate them to the buyers. In any such mechanism, the designer announces

\footnotetext{
${ }^{4}$ Kelso and Crawford (1982) extend the analysis to many-to-one matching models. Sotomayor (2007) introduces the concept of a competitive equilibrium payoff for the multiple-partners assignment game and extends the previous results for this environment.
} 
a competitive equilibrium rule, that is, a function that selects a particular competitive equilibrium for every possible market.

The adoption of a centralized mechanism requires the designer to request the valuations of sellers and buyers who may have an incentive to manipulate their report. This issue was partially addressed in the literature by studying the incentives for truthful reporting by the agents of one side of the market, considering that the agents of the other side do not have any room for strategic behavior. Demange (1982) and Leonard (1983) provide a "non-manipulability theorem" for the assignment game: if the designer uses the buyer-optimal (respectively, the seller-optimal) competitive equilibrium rule then no buyer (respectively, seller) can profit by misstating her (or his) true valuations. ${ }^{5}$ However, Demange and Gale (1985), Roth and Sotomayor (1990), and Pérez-Castrillo and Sotomayor (2013) show that agents have an incentive to manipulate their report if they do not obtain their most preferred competitive equilibrium allocation. ${ }^{6}$

In this paper, we propose and analyze a mechanism (a "game") where both the sellers and the buyers report their valuation and the outcome is given by a competitive equilibrium outcome for the market reported by the agents. In addition, given that there may be several competitive matchings in the market, the buyers are also requested to send a "signal" that will only be used to select among the optimal matchings, whenever several optimal matchings exist. The game has two stages because sellers, simultaneously and non-cooperatively, report their valuations first and, once these are known, buyers, simultaneously and non-cooperatively, are asked to make their reports. Once the agents have played, the competitive price rule maps the matrix of valuations announced by the sellers and the buyers to a competitive price vector for the corresponding market and the matching rule determines a competitive allocation of the objects to the buyers. Although we know that in this game some agents will typically have an incentive to misreport their valuation, we show that the equilibria of the game are, in general, competitive equilibrium outcomes for the true market.

After the sellers report their valuations, the second stage begins. The analysis of

\footnotetext{
${ }^{5}$ Demange and Gale (1985) extend the theorem to a model where the utilities are continuous in money, but are not necessarily linear. Pérez-Castrillo and Sotomayor (2013) prove that buyers (respectively, sellers) do not have an incentive to misreport their valuation if the buyer-optimal (respectively, selleroptimal) competitive equilibrium is used by the designer in a one-to-many (respectively, many-to-one) buyer-seller market.

${ }^{6}$ Papers analyzing the consequences of manipulation in marriage and the college admission models, that is, in models where there are no prices, include Gale and Sotomayor (1985a, 1985b), Roth (1985), Roth and Sotomayor (1990), Sotomayor (2008), Kojima and Pathak (2009), Ma (2010), Sotomayor (2012), and Jaramillo, Kayi, and Klijn (2013).
} 
this stage is interesting in itself because it also allows us to understand the buyers' behavior when the sellers' valuations are given, for example, because they are public knowledge or because sellers cannot manipulate them. We develop the analysis of this stage in two parts. In the first part, we construct specific strategies for the buyers that satisfy that a buyer's report is always lower than her true valuation (which guaranties that she will never pay more for an object than her valuation) and show that they constitute a Nash equilibrium (NE) that leads to the minimum competitive price for the market where the buyers' valuations are the true valuations and the sellers' valuations correspond to those reported. That is, by choosing their reports, buyers can noncooperatively "select" their best competitive outcome, given the sellers' reports.

Since truth-telling is a dominant strategy for the buyers when the minimum competitive price vector is selected, the second part of the analysis of the buyers' behavior concentrates on competitive price rules that do not select the minimum competitive price, whenever several competitive prices exist. For these rules, we fully characterize the set of the buyers' NE. We provide a condition under which the set of NE allocations coincides with the set of competitive equilibrium allocations. This holds, for example, for every market where the number of sellers is larger than the number of buyers. For the other markets, the set of competitive equilibria that are sustained as NE outcomes is smaller than the set of all competitive equilibria.

Finally, we look for the subgame perfect equilibria (SPE) of the two-stage game. Thus, we analyze sellers' strategies and the outcome of the whole game. The main results reveal that, by playing first, sellers are able to achieve an outcome that corresponds to the sellers' optimal competitive equilibrium allocation for the true market. We construct a vector of strategies that constitute an SPE for any competitive equilibrium rule and that lead to the maximum competitive prices. Furthermore, we provide reasonable conditions under which every SPE outcome selects the maximum competitive prices.

In addition to the papers studying the manipulability of competitive equilibrium rules which we reviewed above, our paper is related to the literature that looks for mechanisms (unrelated to competitive equilibrium rules) that implement stable or competitive allocations. For the assignment game, Kameke (1989) and Pérez-Castrillo and Sotomayor (2002) propose variants of sequential mechanisms where sellers choose prices first and then buyers choose objects that implement the maximum competitive equilibrium outcome. In the (many-to-one) job market matching, Alcalde, Pérez- 
Castrillo, and Romero-Medina (1998) offer simple mechanisms that implement the set of stable allocations in SPE when there are at least two firms, and Hayashi and Sakai (2009) study the Nash implementation of the competitive equilibrium correspondence, in addition to proposing mechanisms that lead to this correspondence.

Our paper contributes to the early literature that studies the behavior of buyers or sellers in centralized mechanisms by providing the equilibrium behavior of both buyers and sellers in any centralized competitive equilibrium rule where sellers play first. It also adds to the implementation literature by providing quite simple and direct mechanisms (where agents are asked to report their valuation) that lead to competitive equilibria. In addition to requesting each seller and buyer his or her valuations, the mechanism only requires the buyers to signal some matching(s) to break ties in case several optimal matchings exist for the reported market. The tie breaking rule in our mechanism is quite natural, and it gives enough instruments to the agents to ensure the existence of SPE in the game. ${ }^{7}$

This paper is organized as follows. In section 2 we present the model. In section 3 we introduce the game that we analyze. Section 4 is devoted to a study of the buyers' strategies, and section 5 analyzes the sellers' strategies and the equilibrium of the game. Finally, section 6 concludes.

\section{THE BUYER-SELLER MARKET}

In the buyer-seller market, there is a set $B$ with $m$ buyers, $B=\left\{b_{1}, b_{2}, \ldots, b_{m}\right\}$, and a set $S$ with $n$ sellers, $S=\left\{s_{1}, s_{2}, \ldots, s_{n}\right\}$. Each seller $s_{k}$ owns one indivisible object and each buyer $b_{j}$ wants to buy, at most, one object. We use the same notation for the seller and his object. Letters $j$ and $k$ are assigned to index buyers and objects (or sellers), respectively.

Each seller $s_{k}$ values his object in $r_{k} \geq 0$. Concerning the valuation of the objects for buyers, for each pair $\left(b_{j}, s_{k}\right)$ there is a number $a_{j k}$ (possibly negative) representing the value of object $s_{k}$ for $b_{j}$. We denote by $a_{j}$ the vector of values $a_{j k}$ 's. The valuation matrix of the buyers and the valuation vector of the sellers are denoted by $a$ and $r$, respectively. We use the notation $\boldsymbol{M}(\boldsymbol{a}, \boldsymbol{r})$ for the market $(\boldsymbol{B}, \boldsymbol{S} ; \boldsymbol{a}, \boldsymbol{r})$ where $a$ and $r$ may vary but $B$ and $S$ are fixed.

\footnotetext{
${ }^{7}$ Tie breaking rules are common in mechanism design. See, for instance, Pérez-Castrillo and Sotomayor (2002) for the assignment game. Some papers use alternatives to tie breaking rules to ensure existence of equilibria. For instance, for the combinatorial assignment problem where monetary transfers are not allowed, Budish (2011) proposes the use of "approximate competitive equilibrium" notions.
} 
We denote by $\underline{a}_{j k}(r)$ the potential gains from trade for the pair $\left(b_{j}, s_{k}\right)$, that is, $\underline{a}_{j k}(r) \equiv a_{j k}-r_{k}$ if $a_{j k}-r_{k} \geq 0$ and $\underline{a}(r)_{j k} \equiv 0$ otherwise. We say that object $s_{k}$ is acceptable to $b_{j}$ if $a_{j k}-r_{k} \geq 0$ and it is unacceptable otherwise. If buyer $b_{j}$ purchases object $s_{k}$ at price $p_{k} \geq r_{k}$ her payoff is $a_{j k}-p_{k}$ and the payoff of seller $s_{k}$ is $p_{k}-r_{k}$. When each seller's reservation price is 0 and all objects are acceptable to every buyer, the corresponding model is the Shapley and Shubik's (1972) assignment game. ${ }^{8}$

A matching is an assignment of the objects to the buyers. Formally, a matching for $M(a, r)$ is a matrix $x=\left(x_{j k}\right)$ of zeros and ones. We say that matching $x$ for $M(a, r)$ is feasible if $\sum_{j} x_{j k} \leq 1$ for all $s_{k} \in S, \sum_{k} x_{j k} \leq 1$ for all $b_{j} \in B$, and $\underline{a}(r)_{j k} \geq 0$ if $x_{j k}=1 .{ }^{9}$ That is, a feasible matching assigns an object to at most one buyer and a buyer to at most one object. Moreover, the object assigned to a buyer must be acceptable to her. If $x_{j k}=1$, we say that $b_{j}$ is matched to $s_{k}$ or $s_{k}$ is matched to $b_{j}$, in which case both agents are active at $x$. If $x_{j k}=0$ for all $s_{k} \in S$ (respectively, $b_{j} \in B$ ), we say that $b_{j}$ (respectively, $s_{k}$ ) is unmatched. Of particular interest are optimal matchings. A feasible matching $x$ is optimal if $\sum_{j, k} \underline{a}_{j k}(r) x_{j k} \geq \sum_{j, k} \underline{a}_{j k}(r) x_{j k}^{\prime}$ for all feasible matchings $x^{\prime}$ and if $b_{j}$ and $s_{k}$ are both unmatched, then $s_{k}$ is not acceptable to $b_{j}$.

Feasible allocations for a market $M(a, r)$ involve feasible matchings and feasible prices $p$, that is, prices that are not lower than the sellers' valuations: $p_{k} \geq r_{k}$ for all $s_{k} \in S$. The payoff vector of the buyers corresponding to a feasible allocation $(p, x)$ is $u_{j}=a_{j k}-p_{k}$ if $x_{j k}=1$ and $u_{j}=0$ if $b_{j}$ is unmatched, and we say that the matching $x$ is compatible with the payoff vector $(u, p-r)$ and vice versa.

Given feasible prices $p$, the demand set of buyer $b_{j}$ is the set $D\left(b_{j}, p\right)$ defined as

$$
D\left(b_{j}, p\right)=\left\{s_{k} \in S ; a_{j k}-p_{k} \geq 0 \text { and } a_{j k}-p_{k} \geq a_{j t}-p_{t} \text { for all } s_{t} \in S\right\} .
$$

Thus, among all the acceptable objects that buyer $b_{j}$ can acquire given the price vector $p$, she demands those that maximize her payoff.

Definition 1. A feasible allocation $(p, x)$ for $M(a, r)$ is a competitive equilibrium if (i) every active buyer $b_{j}$ is assigned to some $s_{k} \in D\left(b_{j}, p\right)$; (ii) for all unmatched buyers $b_{j}$ we have that $a_{j k}-p_{k} \leq 0$ for all $s_{k} \in S$, and (iii) $p_{k}=r_{k}$ if $s_{k}$ is unmatched.

\footnotetext{
${ }^{8}$ See Roth and Sotomayor (1990) for an overview of this model.

${ }^{9}$ We use the notation $\sum_{j}$ for the sum over all $b_{j}$ in $B, \sum_{k}$ for the sum over all $s_{k}$ in $S$ and $\sum_{j, k}$ for the sum over all $b_{j}$ in $B$ and $s_{k}$ in $S$.
} 
If $(p, x)$ is a competitive equilibrium allocation for $M(a, r), p$ is called a competitive equilibrium price vector or simply a competitive price and $x$ is called a competitive matching. We denote by $\mathbf{E}(\boldsymbol{a}, \boldsymbol{r})$ the set of competitive equilibrium allocations for $M(a, r)$.

By using linear programming, Shapley and Shubik (1972) prove that $\mathrm{E}(a, r)$ is always non-empty when $r=(0, \ldots, 0)$ and all values $a_{j k}$ 's are non-negative. ${ }^{10}$ They also show the existence of a maximum and of a minimum competitive equilibrium allocation. The same results apply for any reservation price vector $r$ and any valuation matrix $a$. We denote $\left(p^{*}, x\right)$ and $\left(p_{*}, x\right)$, respectively, a maximum and a minimum competitive equilibrium price allocation for $M(a, r)$. The extreme competitive prices $p^{*}(a, r)$ and $p_{*}(a, r)$ can be computed as follows. Denote $V_{a, r}(B, S)$ the maximum total worth of the market $(B, S ; a, r)$, that is, $V_{a, r}(B, S) \equiv \max \sum_{B \times S} \underline{a}(r)_{j k} x_{j k}$, with the maximum to be taken over all feasible matchings $x$ for $M(a, r)$. Then ${ }^{11}$

(i) $p_{k}^{*}(a, r)=V_{a, r}(B, S)-V_{a, r}\left(B, S-\left\{s_{k}\right\}\right)+r_{k}$

(ii) $p_{* k}(a, r)=V_{a, r}\left(B-\left\{b_{j}\right\}, S\right)-V_{a, r}\left(B-\left\{b_{j}\right\}, S-\left\{s_{k}\right\}\right)+r_{k}$ if $x_{j k}=1$ and $p_{* k}(a, r)=r_{k}$ if $s_{k}$ is unmatched at $x$.

Shapley and Shubik (1972) also prove that if a matching is part of a competitive equilibrium allocation, then the matching is optimal. Moreover, any pair composed by a competitive price vector and an optimal matching is a competitive equilibrium allocation.

\section{THE TWO-STAGE GAME}

Competitive equilibria satisfy, among others, the desirable properties of efficiency and envy-freeness - no buyer envies the situation of another one. Thus, it is reasonable to use them as mechanisms for allocating objects to buyers. In any such mechanisms, the designer needs to know the valuations of the sellers and buyers. However, sellers and buyers may have an incentive to report valuations that are not the true ones. We consider this situation as a game, where each seller and buyer is requested to report his or her valuations and the outcome is given by a competitive equilibrium allocation for the reported market. The game also includes a mechanism that allows a selection among the optimal matchings, when their number for the reported market is larger than one.

\footnotetext{
${ }^{10}$ This result was also proved in Sotomayor (2000) by using combinatorial arguments.

${ }^{11}$ See Demange (1982) and Leonard (1983).
} 
We consider a two-stage game where first sellers and then buyers are asked to report their valuations. Given the reports, a competitive equilibrium rule $(\Pi, f)$, composed by a competitive price rule $\Pi$ and a matching rule $f$, will select a competitive allocation for the reported market. Formally, we study the following twostage game $\Gamma(a, r, \Pi, f)$, where the set of players is $B \cup S$ and the players' true valuations are $(a, r)$.

First stage: Sellers play simultaneously. A strategy for seller $s_{k}$ consists of choosing a reservation price $r_{k}^{\prime} \geq 0$ for his object.

Second stage: Knowing the choices of the sellers, buyers play simultaneously. A strategy for buyer $b_{j}$ is a pair of functions $\left(a_{j}{ }_{j}, \sigma_{j}\right)$ defined as follows. For each vector of reservation prices $r^{\prime}=\left(r_{1}^{\prime}, \ldots, r_{m}^{\prime}\right)$, the function $a_{j}^{\prime}$ selects a valuation vector $a_{j}^{\prime}\left(r^{\prime}\right)$ $\equiv\left(a_{j 1}^{\prime}\left(r^{\prime}\right), \ldots, a_{j n}^{\prime}\left(r^{\prime}\right)\right)$ and the function $\sigma_{j}$ gives a signal vector $\sigma_{j}\left(r^{\prime}\right)=\left(\sigma_{j 1}\left(r^{\prime}\right), \ldots\right.$, $\left.\sigma_{j n}\left(r^{\prime}\right)\right)$ of zeros and ones.

To explain the outcome of the game, denote $a^{\prime}\left(r^{\prime}\right) \equiv\left(a_{1}^{\prime}\left(r^{\prime}\right), \ldots, a_{m}^{\prime}\left(r^{\prime}\right)\right)$. Similary, denote the matrix of signals by $\sigma\left(r^{\prime}\right)$. We say that an optimal matching for $M\left(a^{\prime}\left(r^{\prime}\right), r^{\prime}\right)$ is signalized by $\sigma\left(r^{\prime}\right)$ if it maximizes $\sum_{j, k} \sigma_{j k}\left(r^{\prime}\right) y_{j k}$ over all optimal matchings $y$ in $M\left(a^{\prime}\left(r^{\prime}\right), r^{\prime}\right) .{ }^{12}$ Then, given the profile of decisions $\left(r^{\prime} ; a^{\prime}, \sigma\right)$ (where $a^{\prime}=a^{\prime}\left(r^{\prime}\right)$ and $\left.\sigma=\sigma\left(r^{\prime}\right)\right)$, the function $\Pi$ associates the competitive price $\Pi\left(a^{\prime}, r^{\prime}\right)=\left(\Pi_{1}\left(a^{\prime}, r^{\prime}\right), \ldots\right.$, $\left.\Pi_{n}\left(a^{\prime}, r^{\prime}\right)\right)$ for the market $M\left(a^{\prime}, r^{\prime}\right)$. That is, the selection rule $\Pi$ chooses $\Pi\left(a^{\prime}, r^{\prime}\right)$ out of the set of competitive equilibrium prices for $M\left(a^{\prime}, r^{\prime}\right)$. Moreover, the function $f$ associates the optimal matching $f\left(a^{\prime}, r^{\prime}, \sigma\right)$ for $M\left(a^{\prime}, r^{\prime}\right)$, which is a matching signalized by $\sigma$. When there are several signalized optimal matchings, the function $f$ uses some deterministic criterion specified a priori (e.g., all matchings are indexed and the matching rule chooses $x_{i}$ if $x_{i}$ is present and $x_{1}, x_{2}, \ldots, x_{i-1}$ are not present). ${ }^{13}$

Then, the true payoffs of buyer $b_{j}$ and seller $s_{k}$ under the allocation $\left(\Pi\left(a^{\prime}, r^{\prime}\right) ; x\right)$ are, respectively,

$$
\begin{aligned}
& U_{j}\left(\Pi\left(a^{\prime}, r^{\prime}\right) ; x\right)=a_{j k}-\Pi_{k}\left(a^{\prime}, r^{\prime}\right) \text { if } x_{j k}=1 \text { and } \\
& U_{j}\left(\Pi\left(a^{\prime}, r^{\prime}\right) ; x\right)=0 \text { if } b_{j} \text { is unmatched at } x . \\
& V_{k}\left(\Pi\left(a^{\prime}, r^{\prime}\right) ; x\right)=\Pi_{k}\left(a^{\prime}, r^{\prime}\right)-r_{k} \text { if } s_{k} \text { is matched at } x \text { and }
\end{aligned}
$$

\footnotetext{
12 The definition of $\sigma\left(r^{\prime}\right)$ implies that the buyers can signalize any optimal matching $x$ for $M\left(a^{\prime}\left(r^{\prime}\right), r^{\prime}\right)$ by choosing $\sigma\left(r^{\prime}\right)=x$. More generally, they can signalize any subset $S$ of optimal matchings for $M\left(a^{\prime}\left(r^{\prime}\right), r^{\prime}\right)$ by selecting $\sigma_{j k}\left(r^{\prime}\right)=1$ if there is some matching $x$ in $S$ such that $x_{j k}=1$ and $\sigma_{j k}\left(r^{\prime}\right)=0$ otherwise.

${ }^{13}$ We can also consider that each matching in this set has the same probability of being selected.
} 
$V_{k}\left(\Pi\left(a^{\prime}, r^{\prime}\right) ; x\right)=0$ otherwise.

We notice that the sincere strategy profile of the sellers corresponds to $r^{\prime}=r$. The sincere strategy profile of the buyers is given by $a_{j}^{\prime}\left(r^{\prime}\right)=a$ for every $r^{\prime}$ together with an arbitrary $\sigma$.

We are interested in analyzing the class of all two-stage games $\Gamma(a, r, \Pi, f)$ and we use SPE as the solution concept. Thus, we first analyze the buyers' behavior once the sellers have taken their decision and then we study the sellers' equilibrium behavior.

\section{BUYERS' STRATEGIES}

In this section we study the NE of $G\left(a, r^{\prime}, \Pi, f\right)$, the strategic game that starts once the sellers' profile of strategies $r^{\prime}$ has been selected and the outcome function is given by a competitive equilibrium rule $(\Pi, f)$. Since $r^{\prime}$ is fixed throughout this section, we drop it from our notations and we denote $a^{\prime} \equiv a^{\prime}\left(r^{\prime}\right), M\left(a^{\prime}\right) \equiv M\left(a^{\prime}\left(r^{\prime}\right), r^{\prime}\right)$, and so on. Also, $p^{*}\left(a^{\prime}\right)$ and $p_{*}\left(a^{\prime}\right)$ are the maximum and the minimum competitive prices for $M\left(a^{\prime}\right)$ and $u *\left(a^{\prime}\right)$ and $u^{*}\left(a^{\prime}\right)$ are the corresponding buyers' payoffs.

\subsection{PRELIMINARY RESULTS ON THE BUYERS' STRATEGIES}

The results by Demange and Gale (1985) and Sotomayor (1986) and (1990) ensure that a buyer never has an incentive to misrepresent her valuation when the minimum competitive price is selected. That is, $\left(a_{j}, \sigma_{j}\right)$ is a dominant strategy for every buyer $b_{j}$, for any signal $\sigma$ if the competitive price rule $\Pi$ is $\Pi(a)=p_{*}(a)$. On the other hand, Pérez-Castrillo and Sotomayor (2013) show that $(a, \sigma)$ is never a NE if $\Pi(a) \neq p_{*}(a)$.

The incentives for the buyers to misrepresent their true valuations depend on whether the rule leads to the minimum competitive equilibrium allocation. Therefore, while we develop part of the analysis for any competitive equilibrium rule, some results focus on the games $G\left(a, r^{\prime}, \Pi, f\right)$ such that $\Pi(a) \neq p_{*}(a)$ when $M(a)$ has more than one competitive price, a set that we denote by $\mathbf{C}^{+}$. For example, the competitive price rules given by a convex combination of the maximum and the minimum competitive price rules are in $\mathrm{C}^{+}$. That is, $\left\{\Pi ; \Pi=\lambda \Pi^{*}+(1-\lambda) \Pi_{*}\right.$, with $\left.\lambda \in(0,1]\right\} \subseteq \mathrm{C}^{+}$.

If the competitive price rule is in $\mathrm{C}^{+}$, the $\mathrm{NE}$ certainly involve a misrepresentation of the valuations by the buyers. Thus, it is natural to expect that the competitiveness of 
the NE allocations (when they exist) under the true valuations are affected when buyers behave strategically.

We present two examples that motivate our results. Example 1 illustrates a situation in which $(i)$ not every competitive equilibrium for $M(a)$ (in particular, the maximum competitive price) is reached through NE strategies satisfying $a^{\prime} \leq a$; (ii) when $M\left(a^{\prime}\right)$ has several competitive prices then $a^{\prime}$ is not an NE if $\Pi\left(a^{\prime}\right) \neq p_{*}\left(a^{\prime}\right)$; (iii) some NE allocations are not competitive for $M(a)$; (iv) when the NE strategy profile satisfies $a^{\prime} \leq a$ and $M\left(a^{\prime}\right)$ has only one competitive price then the NE is a competitive equilibrium allocation for $M(a)$ and $\Pi(a)=p_{*}(a)$; and $(v)$ the fact that a profile of strategies is or is not an NE under some competitive price rule is independent of which prices are associated with other strategy profiles under this rule.

Example 1. The market is given by $B=\left\{b_{1}, b_{2}\right\}, S=\left\{s_{1}\right\}, r_{1}=0$ and $a=(8,7)$. The set of competitive prices is $[7,8]$. Assume that $\Pi(a) \neq p_{*}(a)=7$. It is a matter of verification that if $a^{\prime}$ is an NE and $a^{\prime} \leq a$ then either $a_{1}^{\prime}=a_{2}^{\prime}=7$ or $a_{1}^{\prime}=7$ and $a_{2}^{\prime}<7$. In the first case, there are two optimal matchings: $x$ with $x_{11}=1$ and $x^{\prime}$ with $x_{21}^{\prime}=1$. The profile $\left(a^{\prime}, \sigma\right)$ is an NE if and only if $\sigma$ signalizes the matching $x$. In this case, $\Pi\left(a^{\prime}\right)=7=p_{*}\left(a^{\prime}\right)=p_{*}(a)$ and $\left(a^{\prime}, \sigma\right)$ is an NE for the game $G\left(a, r^{\prime}, \Pi, f\right)$ for every competitive price rule $\Pi$. In the second case, $x$ is the only optimal matching for $M\left(a^{\prime}\right)$. Then any $\sigma$ signalizes $x$. We can check that for any $\sigma,\left(a^{\prime}, \sigma\right)$ is an NE for the game $G\left(a, r^{\prime}, \Pi, f\right)$ if and only if $\Pi\left(a^{\prime}\right)=a_{2}^{\prime}=p_{*}\left(a^{\prime}\right)$.

In both NE, $\Pi\left(a^{\prime}\right)=p_{*}\left(a^{\prime}\right)$ and $p_{*}(a)$ is competitive for $M\left(a^{\prime}\right)$. However, in the second case $a_{2}^{\prime}<7$, so $\Pi\left(a^{\prime}\right)$ is not a competitive price for $M(a)$. Also, there are competitive prices for $M(a)$ that are not the outcome of any NE $a^{\prime}$ with $a^{\prime} \leq a$ as, for example, $p^{*}(a)=8$. If we relax the assumption that $a^{\prime} \leq a$ then every competitive price of $M(a)$ can be reached via NE strategies. Indeed, if $(p, x) \in \mathrm{E}(a)$, then $\left(a^{\prime}, \sigma\right)$, with $a_{j k}^{\prime}=p_{k}$ for all $\left(b_{j}, s_{k}\right)$ and $\sigma$ signalizes the matching $x$, is an NE and $(p, x)$ is the resulting NE allocation. Finally, this example also illustrates that for any two competitive price rules $\Pi_{1}$ and $\Pi_{2}$ such that $\Pi_{1}\left(a^{\prime}\right)=\Pi_{2}\left(a^{\prime}\right),\left(a^{\prime}, \sigma\right)$ is an NE under $\Pi_{1}$ if and only if $\left(a^{\prime}, \sigma\right)$ is an NE under $\Pi_{2}$. 
When buyers select $a_{j}{ }_{j} \leq a_{j}$ and there is only one seller, it is easy to verify that the only NE payoff is $\left(u^{*}, v_{*}\right)$. Example 1 has shown that this is not always true when $|S|>1$ because, in that example, some NE allocations are not competitive equilibrium allocations for $M(a)$. Example 2 illustrates a market where there are NE outcomes $\left(\Pi\left(a^{\prime}\right), f\left(a^{\prime}, \sigma\right)\right)$ that satisfy that $\Pi\left(a^{\prime}\right)$ is a competitive price for $M(a)$ but it is different from $p_{*}(a)$, even when $a_{j}^{\prime} \leq a_{j}$ for all $b_{j}$.

Example 2. $\left(\left(a^{\prime}, \sigma\right)\right.$ is an NE, $a_{j}^{\prime} \leq a_{j}$ for all $b_{j}, \Pi\left(a^{\prime}\right) \neq p_{*}(a)$ is competitive for $M(a))$ Consider $B=\left\{b_{1}, b_{2}, b_{3}\right\}, S=\left\{s_{1}, s_{2}\right\}, a_{1}=(8,7), a_{2}=(5,6), a_{3}=(4,5)$ and $r=(0,0)$. The minimum competitive equilibrium for this market is $\left(p_{*}=(4,5), x\right)$, where $x_{11}=x_{22}=1$. Let $(\Pi, f)$ be any competitive equilibrium rule. Let buyers choose $\left(a^{\prime}, \sigma\right)$ where $\sigma=x, a_{1}^{\prime}=(5,5), a_{2}^{\prime}=(5,5)$, and $a_{3}^{\prime}=(4,5)$. Then, $p_{*}\left(a^{\prime}\right)=p^{*}\left(a^{\prime}\right)=$ $(5,5)$, so there is only one competitive price in $M\left(a^{\prime}\right)$, and so $\Pi\left(a^{\prime}\right)=(5,5)$. Matching $x$ is optimal for $\mathrm{M}\left(a^{\prime}\right)$, so it is the only matching signalized by $\sigma$. The corresponding true payoff vector for the buyers is $U\left(\Pi\left(a^{\prime}\right) ; x\right)=(3,1,0)$. Clearly $\left(\Pi\left(a^{\prime}\right) ; x\right)$ is a competitive equilibrium under the true valuations. Moreover, we can check that $\left(a^{\prime}, \sigma\right)$ is an NE of the game $G\left(a, r^{\prime}, \Pi, f\right)$ and $\Pi\left(a^{\prime}\right)=(5,5)$, which differs from $p_{*}(a)$.

Theorems 1 and 2 show that the phenomena described in (ii) and (v) of Example 1, respectively, are not accidents. In particular, Theorem 1 states that if $\left(a^{\prime}, \sigma\right)$ is an NE of the game $G\left(a, r^{\prime}, \Pi, f\right)$, where $a^{\prime}$ may or may not be the true buyers' valuations, the selection rule must be giving the buyer-optimal price vector under the reported buyers' valuations, regardless of the choice of the selection rule.

Theorem 1. Let $\left(a^{\prime}, \sigma\right)$ be an NEfor $G\left(a, r^{\prime}, \Pi, f\right)$. Then, $\Pi\left(a^{\prime}\right)=p_{*}\left(a^{\prime}\right)$.

Proof. Suppose by way of contradiction that $\Pi\left(a^{\prime}\right) \neq p_{*}\left(a^{\prime}\right)$. Then, $\Pi_{k}\left(a^{\prime}\right)>p_{* k}\left(a^{\prime}\right) \geq 0$ for an object $s_{k} \in S$, and $s_{k}$ must be matched to some $b_{j}$ under $x \equiv f\left(a^{\prime}, \sigma\right)$. Let $u\left(a^{\prime}\right)$ and $u^{*}\left(a^{\prime}\right)$ be the payoff vectors for the buyers corresponding to $\Pi\left(a^{\prime}\right)$ and $p_{*}\left(a^{\prime}\right)$, respectively. We have that $u_{j}{ }^{*}\left(a^{\prime}\right)>u_{j}\left(a^{\prime}\right)$. Let $\lambda \in \mathrm{R}^{\mathrm{n}}{ }_{+}$be such that

$$
u_{j}^{*}\left(a^{\prime}\right)>\lambda_{j}>u_{j}\left(a^{\prime}\right) \text {. }
$$

Define $\hat{a}^{\prime}$ as follows: $\hat{a}_{j k}^{\prime}=a_{j k}^{\prime}-\lambda_{j}, \hat{a}_{j t}^{\prime}<0$ if $s_{t} \neq s_{k}$, and $\hat{a}_{t}^{\prime}=a_{t}^{\prime}$ if $b_{t} \neq b_{j}$. By (1) and because $x$ is compatible with $p_{*}\left(a^{\prime}\right)$ we can write that $\hat{a}_{j k}^{\prime}=a_{j k}^{\prime}-\lambda_{j}>$ 


$$
\begin{gathered}
a_{j k}^{\prime}-u_{j}^{*}\left(a^{\prime}\right)=p_{* k}\left(a^{\prime}\right) \geq r_{k}^{\prime} \text {. Then, } \\
\hat{a}_{j k}^{\prime}>p_{* k}\left(a^{\prime}\right) \geq r_{k}^{\prime}
\end{gathered}
$$

and $s_{k}$ is acceptable to $b_{j}$ in $M\left(\hat{a}^{\prime}\right)$. We claim that $b_{j}$ is matched under any optimal matching for $M\left(\hat{a}^{\prime}\right)$. In fact, arguing by contradiction, suppose that $b_{j}$ is unmatched under some optimal matching $x^{\prime}$ for $M\left(\hat{a}^{\prime}\right)$. By definition of the function $\boldsymbol{V}_{a^{\prime}}$ we can write: $V_{a^{\prime}}\left(B-\left\{b_{j}\right\}, S\right)=\boldsymbol{V}_{\hat{a}^{\prime}}(B, S) \geq\left(\hat{a}_{j k}^{\prime}-r^{\prime}{ }_{k}\right)+\boldsymbol{V}_{\hat{a}^{\prime}}\left(B-\left\{b_{j}\right\}, S-\left\{s_{k}\right\}\right)>p_{* k}\left(a^{\prime}\right)-r_{k}^{\prime}+$ $V_{a^{\prime}}\left(B-\left\{b_{j}\right\}, S-\left\{s_{k}\right\}\right)$, where (2) was used in the last inequality. However, by the expression of the minimum competitive price we have that $p_{* k}\left(a^{\prime}\right)-r^{\prime}{ }_{k}=V_{a^{\prime}}\left(B-\left\{b_{j}\right\}, S\right)$ $-\boldsymbol{V}_{a^{\prime}}\left(B-\left\{b_{j}\right\}, S-\left\{s_{k}\right\}\right)>p_{* k}\left(a^{\prime}\right)-r^{\prime}{ }_{k}$, which is a contradiction.

Since any object other than $s_{k}$ is not acceptable to $b_{j}$ in $M\left(\hat{a}^{\prime}\right), b_{j}$ must be matched to $s_{k}$ at any optimal matching for $M\left(\hat{a}^{\prime}\right)$. Then, $\Pi_{k}\left(\hat{a}^{\prime}\right) \leq \hat{a}_{j k}^{\prime}=a_{j k}^{\prime}-\lambda_{j}$. However, $a_{j k}^{\prime}-\lambda_{j}<a_{j k}^{\prime}-u_{j}\left(a^{\prime}\right)$ by (1). Therefore, $\Pi_{k}\left(\hat{a}^{\prime}\right)<a_{j k}^{\prime}-u_{j}\left(a^{\prime}\right)=\Pi_{k}\left(a^{\prime}\right)$. Thus, for every optimal matching $y$ for $M\left(\hat{a}^{\prime}\right)$, we have that $U_{j}\left(\Pi\left(\hat{a}^{\prime}\right), y\right)=a_{j k}-\Pi_{k}\left(\hat{a}^{\prime}\right)$ $>\hat{a}_{j k}^{\prime}-\Pi_{k}\left(a^{\prime}\right)=U_{j}\left(\Pi\left(a^{\prime}\right), x\right)$, which contradicts the fact that $\left(a^{\prime}, \sigma\right)$ is an NE for $G\left(a, r^{\prime}, \Pi, f\right)$. Hence, $\Pi\left(a^{\prime}\right)=p_{*}\left(a^{\prime}\right)$.

As stated before, in addition to its intrinsic interest, Theorem 1 helps us to better understand some of the facts discussed in Example 1. In that example, the profile of strategies $a_{1}^{\prime}=7$ and $a_{2}{ }_{2}<7$ constitute an NE if and only if the competitive price rule $\Pi$ satisfies $\Pi\left(a^{\prime}\right)=a_{2}^{\prime}=p_{*}\left(a^{\prime}\right)$. Moreover, in the example, where $\Pi \notin C^{+}$, the matching $x$ is the only optimal matching for $M\left(a^{\prime}\right)$. However, when $\Pi \in C^{+}$, Proposition 1 below implies that, aside very special cases in which no agent is able to obtain a positive payoff, for a vector of reports $a^{\prime}$ to be an NE, the number of optimal matchings must be greater than one.

Proposition 1. Let $\left(a^{\prime}, \sigma\right)$ be an $N E$ of $G\left(a, r^{\prime}, \Pi, f\right)$, where $\Pi \in C^{+}$. Suppose that $a_{j k}^{\prime}-r_{j k}>0$ for at least one pair $\left(b_{j}, s_{k}\right) \in B \times S$. Then, there is more than one optimal matching in $M\left(a^{\prime}\right)$.

Proof. By Theorem 1, $\Pi\left(a^{\prime}\right)=p_{*}\left(a^{\prime}\right)$. Given that $\Pi \in C^{+}, \Pi\left(a^{\prime}\right)=p_{*}\left(a^{\prime}\right)$ is possible only if the set of competitive prices for $M\left(a^{\prime}\right)$ is a singleton. The result then follows from Sotomayor (2002) who shows that if $a_{j k}>r_{k}$ for at least one pair $\left(b_{j}, s_{k}\right) \in B \times S$ and the set of competitive equilibrium prices has only one element, then there are 
several optimal matchings for $M\left(a^{\prime}\right)$.

Theorem 2 states a relationship between the NE of two related games.

Theorem 2. Let $\Pi_{1}$ and $\Pi_{2}$ be competitive price rules. Let $\left(a^{\prime}, \sigma\right)$ be a profile of strategies such that $\Pi_{1}\left(a^{\prime}\right)=\Pi_{2}\left(a^{\prime}\right)$. Then, $\left(a^{\prime}, \sigma\right)$ is an $N E$ of $G\left(\Pi_{1}, f\right)$ if and only if $\left(a^{\prime}, \sigma\right)$ is an $N E$ of $G\left(\Pi_{2}, f\right)$.

Proof. Suppose by way of contradiction that $\left(a^{\prime}, \sigma\right)$ is an NE of $G\left(\Pi_{1}, f\right)$ but it is not an NE of $G\left(\Pi_{2}, f\right)$. Then there is a buyer $b_{j}$ and $\left(\hat{a}^{\prime}, \sigma^{\prime}\right)$ with $\hat{a}_{-j}^{\prime}=a_{-j}^{\prime}$ and $\sigma_{-j}^{\prime}=\sigma_{-j}$ such that $U_{j}\left(\Pi_{2}\left(\hat{a}^{\prime}\right), f\left(\hat{a}^{\prime}, \sigma^{\prime}\right)\right)>U_{j}\left(\Pi_{2}\left(a^{\prime}\right), f\left(a^{\prime}, \sigma\right)\right) .{ }^{14}$ Buyer $b_{j}$ must be matched at $f\left(\hat{a}^{\prime}, \sigma^{\prime}\right)$ to some $s_{k}$ and for some $\lambda>0$ we have that $U_{j}\left(\Pi_{2}\left(\hat{a}^{\prime}\right), f\left(\hat{a}^{\prime}, \sigma^{\prime}\right)\right)-\lambda>$ $U_{j}\left(\Pi_{2}\left(a^{\prime}\right), f\left(a^{\prime}, \sigma\right)\right)$. Moreover, by Theorem 1, $p_{*}\left(a^{\prime}\right)=\Pi_{1}\left(a^{\prime}\right)=\Pi_{2}\left(a^{\prime}\right)$, so

$$
U_{j}\left(\Pi_{2}\left(\hat{a}^{\prime}\right), f\left(\hat{a}^{\prime}, \sigma^{\prime}\right)\right)-\lambda>U_{j}\left(\Pi_{1}\left(a^{\prime}\right), f\left(a^{\prime}, \sigma\right)\right) .
$$

Define $\tilde{a}^{\prime}$ such that $\tilde{a}_{j k}^{\prime}=\Pi_{2 k}\left(\hat{a}^{\prime}\right)+\lambda, \tilde{a}_{j t}^{\prime}=0$ for all $s_{t} \neq s_{k}$ and $\tilde{a}_{-j}^{\prime}=a_{-j}^{\prime}$. It is clear that $\left(\Pi_{2}\left(\hat{a}^{\prime}\right), f\left(\hat{a}^{\prime}, \sigma^{\prime}\right)\right)$ is a competitive equilibrium allocation for $M\left(\tilde{a}^{\prime}\right)$, so $f\left(\hat{a}^{\prime}, \sigma^{\prime}\right)$ is an optimal matching for $M\left(\tilde{a}^{\prime}\right)$. In addition, the corresponding payoff for $b_{j}$ is $\tilde{a}_{j k}^{\prime}-\Pi_{2 k}\left(\hat{a}^{\prime}\right)=\lambda>0$, so $b_{j}$ is matched under every optimal matching for $M\left(\tilde{a}^{\prime}\right)$ (Demange and Gale, 1985). Also, $\tilde{a}_{j k}^{\prime}-\Pi_{2 k}\left(\hat{a}^{\prime}\right)>\tilde{a}_{j t}^{\prime}-\Pi_{2 t}\left(\hat{a}^{\prime}\right)$ for every $s_{t} \neq s_{k}$, so $b_{j}$ only demands $s_{k}$ at prices $\Pi_{2}\left(\hat{a}^{\prime}\right)$. Hence, any competitive matching for $\Pi_{2}\left(\hat{a}^{\prime}\right)$ must allocate $s_{k}$ to $b_{j}$. Given that any optimal matching for $M\left(\tilde{a}^{\prime}\right)$ is competitive for $\Pi_{2}\left(\hat{a}^{\prime}\right)$ we must have that $b_{j}$ is matched to $s_{k}$ at $f\left(\tilde{a}^{\prime}, \sigma^{\prime}\right)$. This implies that $\Pi_{2 k}\left(\tilde{a}^{\prime}\right) \leq \tilde{a}_{j k}^{\prime}=$ $\Pi_{2 k}\left(\hat{a}^{\prime}\right)+\lambda$. Then, $U_{j}\left(\Pi_{2}\left(\tilde{a}^{\prime}\right), f\left(\tilde{a}^{\prime}, \sigma\right)\right)=a_{j k}-\Pi_{2 k}\left(\tilde{a}^{\prime}\right) \geq a_{j k}-\left(\Pi_{2 k}\left(\hat{a}^{\prime}\right)+\lambda\right)=U_{j}\left(\Pi_{2}\left(\hat{a}^{\prime}\right)\right.$, $\left.f\left(\hat{a}^{\prime}, \sigma^{\prime}\right)\right)-\lambda>U_{j}\left(\Pi_{1}\left(a^{\prime}\right), f\left(a^{\prime}, \sigma\right)\right)$, where the last inequality follows from (3). But then $U_{j}\left(\Pi_{2}\left(\tilde{a}^{\prime}\right), f\left(\tilde{a}^{\prime}, \sigma\right)\right)>U_{j}\left(\Pi_{1}\left(a^{\prime}\right), f\left(a^{\prime}, \sigma\right)\right)$, which contradicts the hypothesis that $\left(a^{\prime}, \sigma\right)$ is an NE of $G\left(\Pi_{1}, f\right)$.

Corollaries 1 and 2 below follow easily from theorems 1 and 2, respectively.

Corollary 1. Let $\left(a^{\prime}, \sigma\right)$ be an $N E$ for $G(\Pi, f)$, where $\Pi \in \mathrm{C}^{+}$. Then, there is one and only one competitive equilibrium price for $M\left(a^{\prime}\right)$.

\footnotetext{
${ }^{14}$ We write $a_{-j}^{\prime}$ to denote the decision profile for the buyers other than $b_{j}$.
} 
Corollary 2. Let $\Pi_{1}$ and $\Pi_{2}$ be competitive price rules in $C^{+}$. Then, the profile of strategies $\left(a^{\prime}, \sigma\right)$ is an NE of $G\left(\Pi_{1}, f\right)$ if and only if $\left(a^{\prime}, \sigma\right)$ is an $N E$ of $G\left(\Pi_{2}, f\right)$.

\subsection{MAIN RESULTS ON THE BUYERS' STRATEGIES}

In this subsection, we address the existence and characteristics of the NE of the subgame $G\left(a, r^{\prime}, \Pi, f\right)$. For that purpose, we develop two complementary analyses. In the first one, we concentrate on strategies that satisfy $a^{\prime} \leq a$, which may be a reasonable restriction in several environments. We conclude with the existence result in Theorem 5, which constructs an NE that leads to the minimum competitive price for the market $M(a)$. Then, in the second analysis, whose final results are theorems 6 and 7, we fully characterize the set of NE of $G\left(a, r^{\prime}, \Pi, f\right)$ without restrictions on the type of strategies for any market. In the latest theorems, we focus on competitive price rules in $\mathrm{C}^{+}$.

Before presenting these two analyses, we provide a theorem that is interesting by itself and that will be used in the rest of the section. As Example 1 illustrates, the NE allocation does not always yield a competitive equilibrium for $M(a)$. Theorem 3 shows that the NE is a competitive equilibrium if there is only one competitive price vector in the market defined by the vector of reports.

Theorem 3. Let $\left(a^{\prime}, \sigma\right)$ be an NE of $G\left(a, r^{\prime}, \Pi\right.$, f). If $M\left(a^{\prime}\right)$ has only one competitive equilibrium price then $\Pi\left(a^{\prime}\right)$ is a competitive equilibrium price for $M(a)$.

Proof. Suppose that $\left(\Pi\left(a^{\prime}\right), x\right)$ is not a competitive equilibrium allocation for $M(a)$. For any pair $\left(b_{j}, s_{k}\right)$ with $x_{j k}=1, a_{j k}-\Pi_{k}\left(a^{\prime}\right) \geq 0$ because $b_{j}$ could obtain a zero true payoff by selecting $\hat{a}_{j t}^{\prime}<0$ for every $s_{t}$, which would contradict that $a^{\prime}$ is an NE. Then, there must exist some $b_{j}, s_{t}$ and $s_{k}$, such that $x_{j t}=1$ and $U_{j}\left(\Pi\left(a^{\prime}\right), x\right)=a_{j t}-$ $\Pi_{t}\left(a^{\prime}\right)<a_{j k}-\Pi_{k}\left(a^{\prime}\right)$. Let $\lambda>0$ such that

$$
\Pi_{k}\left(a^{\prime}\right)<a_{j k}-\left(U_{j}\left(\Pi\left(a^{\prime}\right), x\right)+\lambda\right) .
$$

Define $\hat{a}^{\prime}$ as follows: $\hat{a}_{j k}^{\prime}=a_{j k}-\left(U_{j}\left(\Pi\left(a^{\prime}\right), x\right)+\lambda\right), \hat{a}_{j t}^{\prime}<0$ if $s_{t} \neq s_{k}$ and $\hat{a}_{t}^{\prime}=a^{\prime}{ }_{t}$ if $b_{t} \neq b_{j}$. Choose any signal $\sigma^{\prime}$ and denote $y \equiv f\left(\hat{a}^{\prime}, \sigma^{\prime}\right)$. We have that $\hat{a}_{j k}^{\prime}-r_{k}>0$ by (4) and $\hat{a}_{j t}^{\prime}-r_{t}^{\prime}<0$ if $s_{t} \neq s_{k}$. Then, if $b_{j}$ is active, he must be matched with $s_{k}$. We will show that $y_{j k}=1$. Once this is established, it follows that $\Pi_{k}\left(\hat{a}^{\prime}\right) \leq \hat{a}_{j k}^{\prime}$ and then $U_{j}\left(\Pi\left(\hat{a}^{\prime}\right), y\right)=a_{j k}-\Pi_{k}\left(\hat{a}^{\prime}\right) \geq a_{j k}-\hat{a}^{\prime}{ }_{j k}=U_{j}\left(\Pi\left(a^{\prime}\right), x\right)+\lambda>U_{j}\left(\Pi\left(a^{\prime}\right), x\right)$, which contradicts the assumption that $a^{\prime}$ is an NE for $(\Pi, f)$. 
To prove that $y_{j k}=1$, consider the market $M^{\prime} \equiv\left(B-\left\{b_{j}\right\}, S, a_{-j}^{\prime}, r^{\prime}\right)$. Let $p^{*}\left(M^{\prime}\right)$ be the maximum competitive price for $M^{\prime}$. If $y_{j k}=0$, then $b_{j}$ is unmatched under $y$ and $\boldsymbol{V}_{\hat{a}^{\prime}}(B, S)=\boldsymbol{V}_{\hat{a}^{\prime}}\left(B-\left\{b_{j}\right\}, S\right)$. By definition of $\hat{a}^{\prime}$, we have that $\boldsymbol{V}_{\hat{a}^{\prime}}\left(B, S-\left\{s_{k}\right\}\right)=$ $\boldsymbol{V}_{\hat{a}^{\prime}}\left(B-\left\{b_{j}\right\}, S-\left\{s_{k}\right\}\right)$. Using the expression for the maximum equilibrium price, $p^{*}{ }_{k}\left(\hat{a}^{\prime}\right)-$ $r^{\prime}{ }_{k}=\boldsymbol{V}_{\hat{a}^{\prime}}(B, S)-\boldsymbol{V}_{\hat{a}^{\prime}}\left(B, S-\left\{s_{k}\right\}\right)=\boldsymbol{V}_{\hat{a}^{\prime}}\left(B-\left\{b_{j}\right\}, S\right)-\boldsymbol{V}_{\hat{a}^{\prime}}\left(B-\left\{b_{j}\right\}, S-\left\{s_{k}\right\}\right)=p^{*}{ }_{k}\left(M^{\prime}\right)-r^{\prime}{ }_{k}$, so $p^{*}{ }_{k}\left(\hat{a}^{\prime}\right)=p^{*}{ }_{k}\left(M^{\prime}\right)$. On the other hand, Demange and Gale (1985) show that if a set of buyers leaves a market then the maximum equilibrium price does not increase, which implies that $p_{k}^{*}\left(a^{\prime}\right) \geq p_{k}^{*}\left(M^{\prime}\right)$. Therefore,

$$
p_{k}^{*}\left(a^{\prime}\right) \geq p_{k}^{*}\left(\hat{a}^{\prime}\right) \text {. }
$$

$M\left(a^{\prime}\right)$ has only one competitive equilibrium price, hence

$$
\Pi_{k}\left(a^{\prime}\right)=p_{k}^{*}\left(a^{\prime}\right) .
$$

Thus, $p_{k}^{*}\left(\hat{a}^{\prime}\right) \geq \hat{a}_{j k}^{\prime}>\Pi_{k}\left(a^{\prime}\right)=p_{k}^{*}\left(a^{\prime}\right) \geq p_{k}^{*}\left(\hat{a}^{\prime}\right)$, which is absurd, where the first inequality follows from the competitiveness of $\left(p^{*}\left(\hat{a}^{\prime}\right), y\right)$ and from the assumption that $b_{j}$ is unmatched at $y$; in the second inequality we used (4) and the definition of $\hat{a}_{j k}^{\prime}$; the equality is given by (6); and the last inequality follows from (5). Then, $b_{j}$ is necessarily matched under $y$, so $y_{j k}=1$, which concludes the proof.

Corollary 3. Let $\left(a^{\prime}, \sigma\right)$ be an $N E$ of $G\left(a, r^{\prime}, \Pi\right.$, f). If $\Pi \in C^{+}$then $\Pi\left(a^{\prime}\right)$ is $a$ competitive equilibrium price for $M(a)$.

Proof. Corollary 1 implies that $M\left(a^{\prime}\right)$ has only one competitive equilibrium price. Accordingly, the result follows from Theorem 3.

We now proceed to construct strategies satisfying $a_{j k}^{\prime} \leq a$ that constitute NE of $G\left(a, r^{\prime}, \Pi, f\right)$ and whose outcome is the best competitive equilibrium for the buyers. We start with two lemmas. They use the idea of a "super-optimal" matching: we say that a matching $x$ is super-optimal for $M\left(a^{\prime}\right)$ and $M(a)$ if it is optimal for both markets.

Lemma 1. Let $p$ be a competitive equilibrium price for $M(a)$ and $u$ the corresponding payoff for the buyers. Let $a^{\prime}$ be defined by $a_{j k}^{\prime}=a_{j k}-u_{j}$ for all $\left(b_{j}, s_{k}\right)$ $\in B \times S$. Then $p$ is a competitive equilibrium price for $M\left(a^{\prime}\right)$ and all the optimal matchings for $M(a)$ are super-optimal matchings for $M(a)$ and $M\left(a^{\prime}\right)$.

Proof. Let $x$ be an optimal matching for $M(a)$. Then, $(p, x)$ is competitive for $M(a)$. 
For the first assertion, use the competitiveness of $(p, x)$ in $M(a)$ to get that if $x_{j k}=1$, $a_{j k}^{\prime}-p_{k}=\left(a_{j k}-p_{k}\right)-u_{j} \geq\left(a_{j t}-p_{t}\right)-u_{j}=a_{j t}^{\prime}-p_{t}$ for all $s_{t} \in S$. Also, $a_{j k}^{\prime}-p_{k}=a_{j k}-u_{j}-$ $p_{k}=0$, so $s_{k}$ is acceptable to $b_{j}$ in $M\left(a^{\prime}\right)$. Therefore, $(p, x) \in \mathrm{E}\left(a^{\prime}\right)$. For the second assertion, we use the property that a matching in a competitive equilibrium allocation is necessarily optimal. Hence, $x$ is also optimal for $M\left(a^{\prime}\right)$.

Lemma 2. Let $p_{*}$ be the minimum competitive equilibrium price for $M(a)$ and $u^{*}$ the corresponding payoff for the buyers. Let $a^{\prime}$ be defined by $a_{j k}^{\prime}=a_{j k}-u_{j}^{*}$ for all $\left(b_{j}, s_{k}\right) \in B \times S$. Then, the set of competitive equilibrium prices for $M\left(a^{\prime}\right)$ is a singleton and $p_{*}$ is its only element.

Proof. Let $x$ be some optimal matching for $M(a)$. By Lemma 1, $\left(p_{*}, x\right) \in \mathrm{E}\left(a^{\prime}\right)$. Let $p$ be a competitive price for $M\left(a^{\prime}\right)$. If $x_{j k}=1$ then $a_{j k}-p_{k}=a_{j k}-u_{j}^{*}+u_{j}^{*}-p_{k}=\left(a_{j k}^{\prime}-p_{k}\right)$ $+u_{j}^{*} \geq\left(a_{j t}^{\prime}-p_{t}\right)+u_{j}^{*}=a_{j t}-u_{j}^{*}+u_{j}^{*}-p_{t}=a_{j t}-p_{t}$ for any $s_{t} \in S$. Also, $a_{j k}-p_{k}=$ $\left(a^{\prime}{ }_{j k}-p_{k}\right)+u_{j}^{*} \geq 0$. Hence $(p, x) \in \mathrm{E}(a)$, from which it follows that $p \geq p *$. On the other hand, $p_{k} \leq a_{j k}^{\prime}=a_{j k}-u_{j}^{*}=p_{k^{*}}$ if $x_{j k}=1$ and $p_{k}=p_{* k}=r^{\prime}{ }_{k}$ if $s_{k}$ is unmatched at $x$. Then $p \leq p_{*}$, which implies that $p=p_{*}$

Theorem 4 highlights the strong link between the equilibrium of the strategies constructed in Lemma 2 and the super-optimality of the matching generated by the strategies.

Theorem 4. Let $\left(a^{\prime}, \sigma\right)$ be a strategy profile for the game $G\left(a, r^{\prime}, \Pi, f\right)$ such that $a_{j k}^{\prime}=a_{j k}-u_{j}^{*}$ for each pair $\left(b_{j}, s_{k}\right) \in B \times S$. Then $\left(a^{\prime}, \sigma\right)$ is an NE of $G\left(a, r^{\prime}, \Pi, f\right)$ if and only if $f\left(a^{\prime}, \sigma\right)$ is super-optimal for $M\left(a^{\prime}\right)$ and $M(a)$.

Proof. Suppose that $\left(a^{\prime}, \sigma\right)$ is an NE of $G\left(a, r^{\prime}, \Pi, f\right)$. Let $x \equiv f\left(a^{\prime}, \sigma\right)$. By Lemma 2 , the set of competitive prices for $M\left(a^{\prime}\right)$ is a singleton and $p_{*}$ is its only element. Therefore, Theorem 3 implies that $\left(\Pi\left(a^{\prime}\right), x\right) \in \mathrm{E}(a)$ and $x$ is optimal for both $M(a)$ and $M\left(a^{\prime}\right)$.

In the other direction, suppose by way of contradiction that $x$ is a super-optimal matching for $M\left(a^{\prime}\right)$ and $M(a)$ but $\left(a^{\prime}, \sigma\right)$ is not an NE of $G\left(a, r^{\prime}, \Pi, f\right)$. Then, there exists some buyer $b_{j}$, some strategy profile $\hat{a}^{\prime}$ with $\hat{a}_{t}{ }_{t}=a^{\prime}{ }_{t}$ if $b_{t} \neq b_{j}$, and some signal $\sigma$, such that

$$
U_{j}\left(\Pi\left(\hat{a}^{\prime}\right), x^{\prime}\right)>U_{j}\left(\Pi\left(a^{\prime}\right), x\right),
$$


where $x^{\prime}=f\left(\hat{a}^{\prime}, \sigma^{\prime}\right)$.

If $b_{j}$ is active, say $x_{j l}=1$, then $u_{j}\left(a^{\prime}\right)=\hat{a}^{\prime}{ }_{j l}-\Pi_{l}\left(a^{\prime}\right)=a_{j l}-\Pi_{l}\left(a^{\prime}\right)-u_{j}^{*}$. Therefore, $U_{j}\left(\Pi\left(a^{\prime}\right), x\right)=a_{j l}-\Pi_{l}\left(a^{\prime}\right)=u_{j}\left(a^{\prime}\right)+u_{j}^{*}$. If $b_{j}$ is unmatched at $x$ then $u_{j}\left(a^{\prime}\right)=0$ and $U_{j}\left(\Pi\left(a^{\prime}\right), x\right)=0$. By Lemma $1, x$ is optimal for $M(a)$, so $u_{j}^{*}=0$. In both cases,

$$
U_{j}\left(\Pi\left(a^{\prime}\right), x\right)=u_{j}\left(a^{\prime}\right)+u_{j}^{*} \geq 0 .
$$

From (7) and (8) it follows that $U_{j}\left(\Pi\left(\hat{a}^{\prime}\right), x^{\prime}\right)>0$, so $b_{j}$ must be matched to some $s_{k}$ under $x^{\prime}$. Denote $U_{j}^{\prime}\left(\Pi\left(\hat{a}^{\prime}\right), x^{\prime}\right)$ the transfer associated with $x^{\prime}$ in $M\left(a^{\prime}\right)$, that is, $U_{j}^{\prime}\left(\Pi\left(\hat{a}^{\prime}\right), x^{\prime}\right)=a_{j k}^{\prime}-\Pi_{k}\left(\hat{a}^{\prime}\right)$. Then, $U_{j}^{\prime}\left(\Pi\left(\hat{a}^{\prime}\right), x^{\prime}\right)=\left(a_{j k}-u_{j}^{*}\right)-\Pi_{k}\left(\hat{a}^{\prime}\right)=U_{j}\left(\Pi\left(\hat{a}^{\prime}\right), x^{\prime}\right)-$ $u_{j}^{*}>U_{j}\left(\Pi\left(a^{\prime}\right), x\right)-u_{j}^{*}=u_{j}\left(a^{\prime}\right)+u_{j}^{*}-u_{j}^{*}=u_{j}\left(a^{\prime}\right)$, where the inequality and the secondto-last equality follow from (7) and (8), respectively. By Lemma 2, there is only one competitive price in $M\left(a^{\prime}\right)$. Hence, $u_{j}\left(a^{\prime}\right)=u_{j}^{*}\left(a^{\prime}\right)$. This implies $U_{j}^{\prime}\left(\Pi\left(\hat{a}^{\prime}\right), x^{\prime}\right)>u_{j}^{*}\left(a^{\prime}\right)$, which contradicts Proposition 1 applied to $M\left(a^{\prime}\right)$. Hence, $\left(a^{\prime}, \sigma\right)$ is an NE of $G\left(a, r^{\prime}, \Pi, f\right)$.

Theorem 5 shows that the strategies constructed above, which are based on and lead to the minimum competitive price, constitute an NE of the game $G\left(a, r^{\prime}, \Pi, f\right)$, for any competitive equilibrium rule. In this way, the theorem provides a constructive proof of the existence of equilibrium.

Theorem 5. For each pair $\left(b_{j}, s_{k}\right) \in B \times S$, let $a_{j k}^{\prime}=a_{j k}-u_{j}^{*}$ and $\sigma_{j k}=1$ if $x_{j k}=1$ for some optimal matching $x$ for $M(a)$ and $\sigma_{j k}=0$ otherwise. Then, $\left(a^{\prime}, \sigma\right)$ is an NE of any game $G\left(a, r^{\prime}, \Pi, f\right)$. Furthermore, $U\left(\Pi\left(a^{\prime}\right), f\left(a^{\prime}, \sigma\right)\right)=u^{*}$.

Proof. Consider any arbitrary game $G\left(a, r^{\prime}, \Pi, f\right)$. By Lemma 1, the optimal matchings for $M(a)$ are also optimal for $M\left(a^{\prime}\right)$ and vice-versa. By definition of $\sigma$, every optimal matching for $M(a)$ is signalized, which implies that the set of matchings signalized by $\sigma$ coincides with the set of super-optimal matchings for $M\left(a^{\prime}\right)$. Then, $x=f\left(a^{\prime}, \sigma\right)$ is super-optimal for $M(a)$ and $M\left(a^{\prime}\right)$; so $\left(a^{\prime}, \sigma\right)$ is an NE for $G\left(a, r^{\prime}, \Pi, f\right)$. Also, $\Pi\left(a^{\prime}\right)=p_{*}$ by Lemma 2. Therefore, $U_{j}\left(\Pi\left(a^{\prime}\right), x\right)=a_{j k}-p_{k^{*}}=u_{j}^{*}$ if $x_{j k}=1$ and $U_{j}\left(\Pi\left(a^{\prime}\right), x\right)=0=u_{j}^{*}$ if $b_{j}$ is unmatched at $x$, which completes the proof.

The signal vector in the strategies proposed in Theorem 5 allows the buyers to signal matchings that are optimal for the true vector of buyers' valuations. In this way, 
the mechanism always picks super-optimal matchings when $\Pi \in C^{+}$. The role of this signal vector is crucial for guaranteeing the existence of NE of the game $G\left(a, r^{\prime}, \Pi, f\right)$.

Theorem 5 proposes strategies that yield the optimal competitive equilibrium for the buyers as an NE. Example 3 illustrates that there may be NE strategies $\left(a^{\prime}, \sigma\right)$, where $a^{\prime}$ is not defined as in Theorem 5, that yields the optimal competitive equilibrium for the buyers. Thus, coordination problems may still exist.

\section{Example 3. $\left(\left(a^{\prime}, \sigma\right)\right.$ is a Nash equilibrium that is not defined as in Theorem 5, but} $\left.\Pi\left(a^{\prime}\right)=p_{*}(a)\right)$. Consider $B=\left\{b_{1}, b_{2}\right\}, S=\left\{s_{1}, s_{2}\right\}, a_{j}=(4,3)$ for $j=1,2$, and $r_{k}=0$ for $k=1,2$. The buyer-optimal competitive equilibrium payoff for this market is $u_{1}^{*}=$ $u_{2}^{*}=3, v_{* 1}=1, v_{* 2}=0$. For each pair $\left(b_{j}, s_{k}\right) \in B \times S$, let $a_{j k}^{\prime}=a_{j k}-\lambda_{j}$ where $\lambda_{1}=2$ and $\lambda_{2}=3$. Then, $\left(a^{\prime}, \sigma\right)$ is an NE for every competitive equilibrium rule and for every $\sigma$. Furthermore, $\left(u^{*}, v_{*}\right)$ is the corresponding NE payoff. However, $\lambda \neq u^{*}$.

When we look for the NE of the game $G\left(a, r^{\prime}, \Pi, f\right)$ without restrictions on the type of strategies that buyers use, we have more precise information on the set of NE outcomes and the relationship between this set and the set of competitive equilibrium allocations of the market $M(a)$. In particular, we can provide a full characterization of the set of NE outcomes if the competitive price rule is in $\mathrm{C}^{+}$. The main results, which are theorems 6 and 7 below, are immediate consequences of the following lemmas 3 and 4 and previous results. We use the notation $S^{1}(p) \equiv\left\{s_{k} \in S ; p_{k}>r^{\prime}{ }_{k}\right\}$.

Lemma 3. Let $(p, x)$ be a competitive equilibrium of $M(a)$. If $/ B />/ S^{1}(p) /$, then there is an NE of $G\left(a, r^{\prime}, \Pi, f\right)$ whose NE allocation is $(p, x)$.

Proof. Consider the following strategies: $a_{j}^{\prime}=p$ and $\sigma_{j}=x_{j}$ for all $b_{j} \in B$. Given that $p$ is a competitive price of $M(a), p \geq r^{\prime}$. Moreover, if $x_{j k}=1$, then $V_{a^{\prime}}(B, S)=$ $V_{a^{\prime}}\left(B-\left\{b_{j}\right\}, S\right)=\sum_{t}\left(p_{t}-r_{t}^{\prime}\right)$ because $|B|>\left|S^{1}(p)\right|$ allows all the objects in $S^{1}(p)$ to be matched to a buyer (and the surplus of the other objects, according to $a^{\prime}$, is zero). Similarly, $V_{a^{\prime}}\left(B, S-\left\{s_{k}\right\}\right)=V_{a^{\prime}}\left(B-\left\{b_{j}\right\}, S-\left\{s_{k}\right\}\right)=\sum_{t \neq k}\left(p_{t}-r_{t}^{\prime}\right)$ for all $s_{k} \in S$. Therefore, $p^{*}{ }_{k}\left(a^{\prime}\right)-r^{\prime}{ }_{k}=V_{a^{\prime}}(B, S)-V_{a^{\prime}}\left(B, S-\left\{s_{k}\right\}\right)=p_{k}-r^{\prime}{ }_{k}$ and $p_{* k}\left(a^{\prime}\right)-r^{\prime}{ }_{k}=V_{a^{\prime}}\left(B-\left\{b_{j}\right\}, S\right)-$ $V_{a^{\prime}}\left(B-\left\{b_{j}\right\}, S-\left\{s_{k}\right\}\right)=p_{k}-r^{\prime}{ }_{k}$ for all $s_{k} \in S$, which implies that the outcome of the strategy profile $\left(a^{\prime}, \sigma\right)$ is necessarily $\left(\Pi\left(a^{\prime}\right), f\left(a^{\prime}, \sigma\right)\right)=(p, x)$. 
We now prove that $\left(a^{\prime}, \sigma\right)$ is an NE of $G\left(a, r^{\prime}, \Pi, f\right)$. Suppose that player $b_{j}$ deviates to $\left(\hat{a}_{j}^{\prime}, \sigma_{j}^{\prime}\right)$ and denote $\hat{a}^{\prime}=\left(\hat{a}_{j}^{\prime}, a_{-j}^{\prime}\right)$ and $\sigma^{\prime}=\left(\sigma_{j}^{\prime}, \sigma_{-j}\right)$. Given that there are at least $\left|S^{1}(p)\right|$ buyers reporting valuation $p$, any optimal matching for $M\left(\hat{a}^{\prime}\right)$ produces a value for the market at least equal to $\sum_{s k \in S \mid S 1(p)}\left(p_{k}-r^{\prime}{ }_{k}\right)$ and $\Pi_{k}\left(\hat{a}^{\prime}\right) \geq p_{k}$ for all $s_{k} \in S^{1}(p)$. Moreover, $\Pi_{k}\left(\hat{a}^{\prime}\right) \geq r^{\prime}{ }_{k}=p_{k}$ because $\Pi\left(\hat{a}^{\prime}\right)$ is a competitive price vector. Therefore, $a_{j k}-\Pi_{k}\left(\hat{a}^{\prime}\right) \leq a_{j k}-p_{k} \leq U_{j}(p, x)=U_{j}\left(\Pi\left(a^{\prime}\right), f\left(a^{\prime}, \sigma\right)\right)$ for any $s_{k} \in S$. Thus, $b_{j}$ cannot improve by deviating to $\hat{a}^{\prime}$.

Lemma 4. Let $(p, x)$ be a competitive equilibrium of $M(a)$. If $/ B / \leq / S^{1}(p) /$, then there is no NE of $G\left(a, r^{\prime}, \Pi, f\right)$ whose outcome is $(p, x)$.

Proof. Suppose $\left(a^{\prime}, \sigma\right)$ is an NE of $G\left(a, r^{\prime}, \Pi, f\right)$ and $\Pi\left(a^{\prime}\right)=p$. By Theorem 1 , we have that $p=p_{*}\left(a^{\prime}\right)$. Demange and Gale (1985) and Pérez-Castrillo and Sotomayor (2013) imply that the number of buyers must be larger than the number of sellers that obtain positive surplus, that is, $|B|>\left|S^{1}(p)\right|$, which is not possible.

For some markets, Lemma 3 allows us to state that the set of competitive equilibria coincides with the set of NE allocations. However, there are markets where the set of competitive equilibria that are sustained as NE outcomes of $G\left(a, r^{\prime}, \Pi, f\right)$ is smaller than the set of all competitive equilibria, although larger than the set of competitive equilibrium with minimum prices. We first illustrate that this can happen in Example 4 and then we state the general results.

Example 4. Let $B=\left\{b_{1}, b_{2}\right\}, S=\left\{s_{1}, s_{2}\right\}, a_{11}=3, a_{12}=3, a_{21}=4, a_{22}=8, r_{1}^{\prime}=r_{2}^{\prime}=$ 0 . It is easy to check that a vector of prices $p$ is competitive if and only if $p_{1} \leq 3$, $p_{2} \geq p_{1}$ and $p_{2} \leq 4+p_{1}$. The minimum competitive price is $p_{*}=(0,0)$ and the set of competitive prices that are outcome of some $\mathrm{NE}$ of $G\left(a, r^{\prime}, \Pi, f\right)$ is the set $\left\{\left(0, p_{2}\right) ; p_{2} \in[0,4]\right\}$, which is strictly smaller than the set of competitive equilibria.

Denote $S^{o}=\left\{s_{k} \in S ; p_{k}>r^{\prime}{ }_{k}\right.$ for some $\left.(p, x) \in E(a)\right\}$. Sellers in $S^{o}$ are active in every competitive equilibrium, so $|B| \geq\left|S^{o}\right|$ always.

Theorem 6. If $/ B />/ S^{o} /$ and $\Pi \in C^{+}$, then the set of $N E$ allocations of $G\left(a, r^{\prime}, \Pi, f\right)$ 
coincides with the set of competitive equilibrium allocations of $M(a)$.

Proof. For every $(p, x) \in E(a)$, it happens that $S^{1}(p) \subseteq S^{o}$. Hence, $|B|>\left|S^{o}\right|$ implies $|B|>\left|S^{1}(p)\right|$ for every $(p, x) \in E(a)$. According to Lemma 3, this implies that all competitive equilibrium allocations of $M(a)$ are NE allocations of $G\left(a, r^{\prime}, \Pi, f\right)$. On the other hand, Theorem 3 shows that all NE allocations of $G\left(a, r^{\prime}, \Pi, f\right)$ are competitive equilibrium allocations of $M(a)$ if $\Pi \in C^{+}$.

Corollary 4. If $/ B />/ S /$ and $\Pi \in C^{+}$, then the set of $N E$ allocations of $G\left(a, r^{\prime}, \Pi, f\right)$ coincides with the set of competitive equilibrium allocations of $M(a)$.

Theorem 7. If $/ B /=/ S^{o} /$ and $\Pi \in C^{+}$, then the set of $N E$ outcomes of $G\left(a, r^{\prime}, \Pi, f\right)$ corresponds to the set $\left\{(p, x) ;(p, x) \in E(a)\right.$ and $p_{k}=r^{\prime}{ }_{k}$ for some $\left.s_{k} \in S^{o}\right\}$, which contains the set of minimum competitive price allocations of $M(a)$.

Proof. First, Theorem 3 shows that all NE allocations of $G\left(a, r^{\prime}, \Pi, f\right)$ are competitive equilibrium allocations of $M(a)$ if $\Pi \in C^{+}$. Second, consider $(p, x) \in E(a)$, for which $S^{1}(p) \subseteq S^{o}$. If $p_{k}>{r^{\prime}}_{k}$ for all $s_{k} \in S^{o}, S^{1}(p)=S^{o}$ and, applying Lemma 4 , there is no NE of $G\left(a, r^{\prime}, \Pi, f\right)$ whose outcome is $(p, x)$. On the other hand, if $p_{k}=r^{\prime}{ }_{k}$ for some $s_{k} \in S^{o}$, then $S^{1}(p) \subset S^{o}$ and, applying Lemma 3, there is an NE of $G\left(a, r^{\prime}, \Pi, f\right)$ whose outcome is $(p, x)$. Finally, Theorem 5 implies that the set $\{(p, x) ;(p, x) \in E(a)$ and $p_{k}=r_{k}{ }_{k}$ for some $\left.s_{k} \in S^{o}\right\}$ includes the set of minimum competitive price allocations of $M(a)$.

\section{SELLERS' STRATEGIES AND EQUILIBRIUM OF THE GAME}

The analysis of section 4 shows that, for any sellers' choice $r^{\prime}$, buyers can get $u^{*}\left(r^{\prime}\right)$ by playing the equilibrium strategies $a^{\prime}$ identified in Theorem 5 . We now show that, in equilibrium, sellers can reverse this situation.

We use some of the results in section 4 first to construct an SPE for the two-stage game $\Gamma(\Pi, f)$ for any competitive equilibrium rule $(\Pi, f)$ and then to characterize the outcome of all the SPE of the game under certain conditions. The construction of an SPE uses two instrumental lemmas, where we denote $p^{*}$ and $p_{*}$, respectively, the maximum and the minimum competitive prices for the true market $M(a, r)$. 
Lemma 5. $p^{*}$ is the only competitive equilibrium price for market $M\left(a, r^{\prime}=p^{*}\right)$.

Proof. Let $x$ be an optimal matching for $M(a, r)$. Then, $\left(p^{*}, x\right) \in \mathrm{E}(a, r)$. Clearly, $\left(p^{*}, x\right) \in \mathrm{E}\left(a, p^{*}\right)$ also, so $x$ is an optimal matching for $M\left(a, p^{*}\right)$. Let $p$ be some competitive price for $M\left(a, p^{*}\right)$. We claim that $p=p^{*}$. In fact, the feasibility of $p$ in $M\left(a, p^{*}\right)$ implies that

$$
p_{k} \geq p^{*}{ }_{k} \geq r_{k} \text { for all } s_{k} \in S .
$$

Then $p$ is feasible for $M(a, r)$. Moreover, if $s_{k}$ is unmatched at $x$ then $p_{k}=p^{*}{ }_{k}=$ $r_{k}$, so $p_{k}=r_{k}$. The competitiveness of $(p, x)$ in $M(a, r)$ therefore follows from the competitiveness of $(p, x)$ in $M\left(a, p^{*}\right)$. Then, the maximality of $p^{*}$ in $M(a, r)$ implies

$$
p^{*}{ }_{k} \geq p_{k} \text { for all } s_{k} \in S \text {. }
$$

By (9) and (10) we obtain that $p^{*}=p$.

Lemma 6. Let $r^{\prime}$ be a vector of reservation prices for the sellers such that $r^{\prime}{ }_{k}>p^{*}{ }_{k}$ for some $s_{k} \in S$ and $r_{t}^{\prime}=p^{*}{ }_{t}$ for all $s_{t} \in S-\left\{s_{k}\right\}$. Then, $s_{k}$ is unmatched at any competitive equilibrium for $M\left(a, r^{\prime}\right)$.

Proof. If $(p, x) \in \mathrm{E}\left(a, r^{\prime}\right)$ and $s_{k}$ is matched at $x$, then $(p, x) \in \mathrm{E}\left(a, p^{*}\right)$ also, and so $p=p^{*}$ by Lemma 5 . However, $p_{k} \geq r^{\prime}{ }_{k}>p^{*}{ }_{k}$, which is a contradiction.

Theorem 8 proposes strategies for the sellers and the buyers and shows that they constitute an SPE of the game $\Gamma(a, r, \Pi, f)$, for any competitive equilibrium rule $(\Pi, f)$. In this SPE, the sellers report valuations that correspond to the maximum competitive prices for the true market and the buyers follow the strategy proposed in Theorem 5, which leads to the minimum competitive prices for the "reported" market. The fact that sellers choose first gives them a crucial advantage and the SPE allocation corresponds to the sellers' optimal competitive equilibrium allocation for the true market.

Theorem 8. Let ( $\left.a^{\prime}(),. \sigma().\right)$ be defined as follows: $a_{j k}^{\prime}\left(r^{\prime}\right)=a_{j k}-u_{j}^{*}\left(a, r^{\prime}\right)$ for each $\left(b_{j}, s_{k}\right) \in B \times S$ and for all $r^{\prime}, \sigma_{j k}\left(r^{\prime}\right)=1$ if $x_{j k}=1$ for some optimal matching $x$ for $M\left(a, r^{\prime}\right)$ and $\sigma_{j k}\left(r^{\prime}\right)=0$ otherwise. Then, $\left(p^{*}, a^{\prime}(),. \sigma().\right)$ constitutes an SPE of $\Gamma(a, r, \Pi, f)$ for any competitive equilibrium rule $(\Pi, f)$. At this SPE, the true payoffs of buyers and sellers are, respectively, $u *$ and $p^{*}-r$. 
Proof. By Theorem 5, $\left(a^{\prime}\left(r^{\prime}\right), \sigma\left(r^{\prime}\right)\right)$ is an NE of the subgame $G\left(r^{\prime},(\Pi, f)\right)$, for every $r^{\prime}$. Moreover, $\Pi\left(a^{\prime}\left(r^{\prime}\right), r^{\prime}\right)=p_{*}\left(a, r^{\prime}\right)$ and $U\left(\Pi\left(a^{\prime}\left(r^{\prime}\right), r^{\prime}\right), f\left(a^{\prime}\left(r^{\prime}\right), r^{\prime}, \sigma\left(r^{\prime}\right)\right)\right)=u^{*}\left(a, r^{\prime}\right)$. In particular, when $r^{\prime}=p^{*},\left(a^{\prime}\left(p^{*}\right), \sigma\left(p^{*}\right)\right)$ is an NE of $G\left(p^{*},(\Pi, f)\right)$, and $\Pi\left(a^{\prime}\left(p^{*}\right)\right)=$ $p_{*}\left(p^{*}\right)$, which is the minimum competitive price of $M\left(a, p^{*}\right)$. By Lemma $5, p^{*}$ is the only competitive price for $M\left(a, p^{*}\right)$, so $\Pi\left(a^{\prime}\left(p^{*}\right)\right)=p^{*}$ and $u^{*}\left(p^{*}\right)=u_{*}\left(p^{*}\right)=u_{*}$. Also, $U\left(\Pi\left(a^{\prime}\left(r^{\prime}\right)\right), f\left(a^{\prime}\left(r^{\prime}\right), r^{\prime}, \sigma\left(r^{\prime}\right)\right)\right)=u *$ and $V\left(\Pi\left(a^{\prime}\left(r^{\prime}\right), r^{\prime}\right), f\left(a^{\prime}\left(r^{\prime}\right), r^{\prime}, \sigma\left(r^{\prime}\right)\right)\right)=p^{*}-r$.

Thus, proving that $\left(p^{*}, a^{\prime}(),. \sigma().\right)$ is an SPE only requires showing that $p^{*}{ }_{k}$ is a best response for every seller $s_{k} \in S$. By playing $p^{*}{ }_{k}$ seller $s_{k}$ gets $p^{*}{ }_{k}$. If $s_{k}$ selects any other $r_{k}^{\prime}$, the competitive price is $\Pi\left(a^{\prime}\left(r^{\prime}\right), r^{\prime}\right)=p_{*}\left(r^{\prime}\right)$, where $r^{\prime} \equiv\left(r^{\prime}{ }_{k}, p^{*}{ }_{-k}\right)$.

There are two cases. First, if $r^{\prime}{ }_{k}<p^{*}{ }_{k}$ then $p_{*}\left(r^{\prime}\right) \leq p_{*}\left(p^{*}\right)=p^{*}$ because the maximum equilibrium price is not decreasing in the sellers' reservation values (Demange and Gale, 1985). Hence, $\Pi\left(a^{\prime}\left(r^{\prime}\right), r^{\prime}\right)_{k}=p_{*}\left(r^{\prime}\right)_{k} \leq p^{*}{ }_{k}$, so $s_{k}$ cannot profit by deviating from $p^{*}$. Second, if $r_{k}^{\prime}>p_{k}^{*}$, it follows from Lemma 6 that $s_{k}$ is unmatched at any competitive equilibrium for $M\left(a, r^{\prime}\right)$, so he obtains a true payoff of $0 \leq p^{*}{ }_{k}-r_{k}$. Therefore, $s_{k}$ cannot profit by deviating from $p_{k}^{*}$ and $\left(a^{\prime}\left(r^{\prime}\right), p^{*}, \sigma\left(r^{\prime}\right)\right)$ is an SPE.

Theorem 9 shows a stronger result than Theorem 8 when we restrict attention to competitive price rules in the set $\mathrm{C}^{+}$. For any such rule, the strategy vector where sellers select the maximum competitive prices for the true market and the buyers follow any $\mathrm{NE}$ of the continuation game is an SPE of the game.

Theorem 9. Consider any competitive price rule $\Pi \in C^{+}$. Let $\left(a^{\prime}\left(r^{\prime}\right), \sigma\left(r^{\prime}\right)\right)$ be an NE of the subgame $G\left(r^{\prime},(\Pi, f)\right)$, for every selection $r^{\prime}$ by the sellers. Then, $\left(p^{*}, a^{\prime}(),. \sigma().\right)$ is an SPE of $\Gamma(a, r, \Pi, f)$. At this SPE, the true payoffs of buyers and sellers are, respectively, $u_{*}$ and $p^{*}-r$.

Proof. By Theorem 3, $\left(\Pi\left(a^{\prime}\left(p^{*}\right), p^{*}\right), f\left(a^{\prime}\left(p^{*}\right), p^{*}, \sigma\left(p^{*}\right)\right)\right) \in \mathrm{E}\left(a, p^{*}\right)$, so $\Pi\left(a^{\prime}\left(p^{*}\right), p^{*}\right)=$ $p^{*}$ and $x \equiv f\left(a^{\prime}\left(p^{*}\right), p^{*}, \sigma\left(p^{*}\right)\right)$ is optimal for $M\left(a, p^{*}\right)$. Then, $U\left(\Pi\left(a^{\prime}\left(p^{*}\right), p^{*}\right), x\right)=u_{*}$ and $V\left(\Pi\left(a^{\prime}\left(p^{*}\right), p^{*}\right), x\right)=p^{*}-r$.

The rest of the proof follows the same arguments as the proof of Theorem 8 .

Theorems 8 and 9 construct SPE whose outcome corresponds to the sellers' optimal competitive equilibrium allocation for the true market. Is this allocation the 
unique SPE of the game $\Gamma(a, r, \Pi, f)$ ? Theorem 10, which constitutes our final result, states that this outcome is in fact the unique SPE outcome of any game $\Gamma(a, r, \Pi, f)$ for price rules $\Pi$ in $C^{+}$provided that the sellers' strategies satisfy two intuitive conditions: a seller's report cannot be lower than his true valuation, and it is equal to the true valuation if he does not sell his object at the SPE even reporting that valuation.

Theorem 10 makes use of Lemma 7, which states the outcome of any SPE when the price rule is in $\mathrm{C}^{+}$as a function of the equilibrium strategy by the sellers.

Lemma 7. Consider any competitive price rule $\Pi \in C^{+}$. If $\left(r^{\prime}, a^{\prime}(),. \sigma().\right)$ is an SPE of $\Gamma(a, r, \Pi, f)$, then $V\left(\Pi\left(a^{\prime}\left(r^{\prime}\right), r^{\prime}\right), f\left(a^{\prime}\left(r^{\prime}\right), r^{\prime}, \sigma\left(r^{\prime}\right)\right)\right)=p^{*}\left(a, r^{\prime}\right)-r$ and $f\left(a^{\prime}\left(r^{\prime}\right), r^{\prime}, \sigma\left(r^{\prime}\right)\right)$ is optimal for $M\left(a, r^{\prime}\right)$.

Proof. Since $\left(a^{\prime}\left(r^{\prime}\right), \sigma\left(r^{\prime}\right)\right)$ is an NE for the buyers given $r^{\prime}$ and $\Pi \in \mathrm{C}^{+}$, Theorem 3 implies that $\left(\Pi\left(a^{\prime}\left(r^{\prime}\right), r^{\prime}\right), f\left(a^{\prime}\left(r^{\prime}\right), r^{\prime}, \sigma\left(r^{\prime}\right)\right)\right) \in \mathrm{E}\left(a, r^{\prime}\right)$, so $x^{\prime} \equiv f\left(a^{\prime}\left(r^{\prime}\right), r^{\prime}, \sigma\left(r^{\prime}\right)\right)$ is optimal for $M\left(a, r^{\prime}\right)$, and it is compatible with $p^{*}\left(a, r^{\prime}\right)$. Now, suppose by contradiction that $\Pi\left(a^{\prime}\left(r^{\prime}\right), r^{\prime}\right) \neq p^{*}\left(r^{\prime}\right)$. Then, there is some seller $s_{k}$ such that $p_{k}^{*}\left(a, r^{\prime}\right)>\Pi\left(a^{\prime}\left(r^{\prime}\right)\right.$, $\left.r^{\prime}\right)_{k} \geq r^{\prime}{ }_{k}$ so $p_{k}^{*}\left(a, r^{\prime}\right)>r^{\prime}{ }_{k}$ and $s_{k}$ is matched under $x^{\prime}$. Choose $\hat{r}^{\prime}{ }_{k}$ so that

$$
p_{k}^{*}\left(a, r^{\prime}\right)>\hat{r}_{k}^{\prime}>\Pi\left(a^{\prime}\left(r^{\prime}\right), r^{\prime}\right) \geq r_{k}^{\prime} .
$$

Suppose that seller $s_{k}$ deviates from $r^{\prime}$ by choosing $\hat{r}_{k}^{\prime}$, and set $\hat{r}^{\prime} \equiv\left(\hat{r}_{k}^{\prime}, r_{-k}^{\prime}\right)$. Because $\left(r^{\prime}, a^{\prime}(),. \sigma().\right)$ is an SPE of $\Gamma(a, r, \Pi, f)$, it is the case that $\left(a^{\prime}\left(\hat{r}^{\prime}\right), \sigma\left(\hat{r}^{\prime}\right)\right)$ is an $\mathrm{NE}$ for the buyers and $\left(\Pi\left(a^{\prime}\left(\hat{r}^{\prime}\right), \hat{r}^{\prime}\right), f\left(a^{\prime}\left(\hat{r}^{\prime}\right), \hat{r}^{\prime}, \sigma\left(\hat{r}^{\prime}\right)\right)\right) \in \mathrm{E}\left(a, \hat{r}^{\prime}\right)$. On the other hand, given that $\hat{r}^{\prime}>r^{\prime}, p_{k}^{*}\left(a, \hat{r}^{\prime}\right) \geq p_{k}^{*}\left(a, r^{\prime}\right)$, so $p_{k}^{*}\left(a, \hat{r}^{\prime}\right)>\hat{r}_{k}^{\prime}$ by (11), which implies that $s_{k}$ is matched at $x^{\prime \prime} \equiv f\left(a^{\prime}\left(\hat{r}^{\prime}\right), \hat{r}^{\prime}, \sigma\left(\hat{r}^{\prime}\right)\right)$. Then, $s_{k}$ 's true payoff is $V_{k}\left(\Pi\left(a^{\prime}\left(\hat{r}^{\prime}\right), \hat{r}^{\prime}\right), x^{\prime \prime}\right)=$ $\Pi\left(a^{\prime}\left(\hat{r}^{\prime}\right), \hat{r}^{\prime}\right)_{k}-r_{k} \geq \hat{r}^{\prime}{ }_{k}-r_{k}>\Pi\left(a^{\prime}\left(r^{\prime}\right), r^{\prime}\right)_{k}-r_{k}=V_{k}\left(\Pi\left(a^{\prime}\left(r^{\prime}\right), x\right)\right.$, from which it follows that $s_{k}$ is not playing his best response, contradicting that $\left(r^{\prime}, a^{\prime}(),. \sigma().\right)$ is an SPE. Hence, $\Pi\left(a^{\prime}\left(r^{\prime}\right), r^{\prime}\right)=p^{*}\left(a, r^{\prime}\right)$, so $V\left(\Pi\left(a^{\prime}\left(r^{\prime}\right), r^{\prime}\right), x\right)=p^{*}\left(a, r^{\prime}\right)-r$.

Theorem 10. Consider any competitive price rule $\Pi \in C^{+}$and let $\left(r^{\prime}, a^{\prime}(),. \sigma().\right)$ be an SPE of $\Gamma\left(a, r, \Pi\right.$, f). If $r^{\prime} \geq r$ and $r^{\prime}{ }_{k}=r_{k}$ for every $s_{k}$ unmatched at $f\left(a^{\prime}\left(r^{\prime}\right), r^{\prime}\right.$, $\left.\sigma\left(r^{\prime}\right)\right)$, then $V\left(\Pi\left(a^{\prime}\left(r^{\prime}\right), r^{\prime}\right), f\left(a^{\prime}\left(r^{\prime}\right), r^{\prime}, \sigma\left(r^{\prime}\right)\right)\right)=p^{*}(a, r)-r$ and $f\left(a^{\prime}\left(r^{\prime}\right), r^{\prime}, \sigma\left(r^{\prime}\right)\right)$ is optimal for $M(a, r)$.

Proof. Denote $x^{\prime} \equiv f\left(a^{\prime}\left(r^{\prime}\right), r^{\prime}, \sigma\left(r^{\prime}\right)\right)$. By Theorem 3 we know that $x^{\prime}$ is optimal for $M\left(a, r^{\prime}\right)$. We claim that $\left(p^{*}\left(a, r^{\prime}\right), x^{\prime}\right) \in \mathrm{E}(a, r)$. First, $p^{*}\left(a, r^{\prime}\right) \geq r^{\prime} \geq r$, so $p^{*}\left(a, r^{\prime}\right)$ is 
feasible for $M(a, r)$. Second, the competitiveness of $p^{*}\left(a, r^{\prime}\right)$ in $M\left(a, r^{\prime}\right)$ implies its competitiveness in $M(a, r)$. Finally, every unsold object at $x^{\prime}$ gets its reservation price: $r_{k}^{\prime}=r_{k}$. Then, $x^{\prime}$ is also optimal for $M(a, r)$.

We notice that on one hand $p^{*}\left(a, r^{\prime}\right) \leq p^{*}(a, r)$ by the maximality of $p^{*}$ in $M(a, r)$. On the other hand, $p^{*}\left(a, r^{\prime}\right) \geq p^{*}(a, r)$ because $r^{\prime} \geq r$. Hence, $p^{*}\left(a, r^{\prime}\right)=$ $p^{*}(a, r)$. Now use Theorem 10 to obtain that $\Pi\left(a^{\prime}\left(r^{\prime}\right), r^{\prime}\right)=p^{*}\left(a, r^{\prime}\right)=p^{*}(a, r)$, and then $V\left(\Pi\left(a^{\prime}\left(r^{\prime}\right), r^{\prime}\right), x^{\prime}\right)=p^{*}(a, r)-r$.

Our final example shows that if seller $s_{k}$ is unmatched at some SPE outcome and $r^{\prime}{ }_{k}>r_{k}$, the conclusion of Theorem 10 is not always true. As we see in the example below, by playing $r_{k}^{\prime}>r_{k}$ he might make some matched agent better off without making himself worse off.

Example $5\left(\left(r^{\prime}, a^{\prime}(),. \sigma().\right)\right.$ is an SPE of $\Gamma(a, r, \Pi, f)$ with $\Pi \in C^{+}$but $V\left(a^{\prime}\left(r^{\prime}\right), f\left(r^{\prime}, a^{\prime}(),. \sigma().\right)>p^{*}(a, r)-r ; \Pi\left(a^{\prime}\left(r^{\prime}\right), r^{\prime}\right)\right.$ is a competitive price for $M\left(a, r^{\prime}\right)$ but it is not competitive for $M(\boldsymbol{a}, \boldsymbol{r}))$. Consider $B=\left(b_{1}, b_{2}, b_{3}\right), \quad S=\left(s_{1}, s_{2}, s_{3}, s_{4}\right)$, $a_{1}=(5,4,0,0.5), a_{2}=(0,5,0,0)$ and $a_{3}=(4,10,5,4.5), r=(0,0,0,0)$. Then, $p^{*}=(4.5,5,0,0)$ and $p_{*}=(0,5,0,0)$. Consider also the competitive price rule $\Pi \in C^{+}$ and let $r^{\prime}=(0,0,0,0.5)$. The optimal matchings for $M\left(a, r^{\prime}\right)$ are $x$ and $x^{\prime}$, where $x_{11}=x_{22}=x_{33}=1$ and $x_{11}^{\prime}=x_{23}^{\prime}=x_{32}=1$.

Define $\left(a^{\prime}, \sigma\right)$ as follows: $a_{1}^{\prime}\left(r^{\prime}\right)=a_{2}^{\prime}\left(r^{\prime}\right)=(5,5,0,0.5), a_{3}^{\prime}\left(r^{\prime}\right)=(4,10,5,5)$, $\sigma_{j k}\left(r^{\prime}\right)=1$ if $x_{j k}=1$ or $x_{j k}^{\prime}=1$ and $\sigma_{j k}\left(r^{\prime}\right)=0$ otherwise. For $\hat{r}^{\prime} \neq r^{\prime}$, let $\left(a^{\prime}\left(\hat{r}^{\prime}\right), \sigma\left(\hat{r}^{\prime}\right)\right)$ be the NE given by Theorem 5 by making $u^{*}=u^{*}\left(\hat{r}^{\prime}\right)$. We will show that $\left(r^{\prime}, a^{\prime}(),. \sigma().\right)$ is an SPE but $V\left(\Pi\left(a^{\prime}\left(r^{\prime}\right), r^{\prime}\right), f\left(a^{\prime}\left(r^{\prime}\right), r^{\prime}, \sigma\left(r^{\prime}\right)\right)\right)=(5,5,0,0)>p^{*}-r$.

First notice that the optimal matchings for $M\left(a^{\prime}\left(r^{\prime}\right), r^{\prime}\right)$ signalized by $\sigma\left(r^{\prime}\right)$ are $x$ and $x^{\prime}$. Both matchings are super-optimal for $M\left(a^{\prime}\left(r^{\prime}\right), r^{\prime}\right)$ and $M\left(a, r^{\prime}\right)$.

It is a matter of verification that in the market $M\left(a^{\prime}\left(r^{\prime}\right), r^{\prime}\right)$ we have that $p^{*}\left(a^{\prime}\left(r^{\prime}\right), r^{\prime}\right)=p_{*}\left(a^{\prime}\left(r^{\prime}\right), r^{\prime}\right)=(5,5,0,0.5)$, so seller $s_{4}$ is unmatched at any optimal matching chosen by $f\left(a^{\prime}\left(r^{\prime}\right), r^{\prime}, \sigma\left(r^{\prime}\right)\right), V\left(\Pi\left(a^{\prime}\left(r^{\prime}\right), r^{\prime}\right), f\left(a^{\prime}\left(r^{\prime}\right), r^{\prime}, \sigma\left(r^{\prime}\right)\right)\right)=(5,5,0,0)$ and $U\left(\Pi\left(a^{\prime}\left(r^{\prime}\right), r^{\prime}\right), f\left(a^{\prime}\left(r^{\prime}\right), r^{\prime}, \sigma\left(r^{\prime}\right)\right)\right)=(0,0,5)$. To prove that $\left(a^{\prime}\left(r^{\prime}\right), \sigma\left(r^{\prime}\right)\right)$ is an NE for the buyers suppose, by way of contradiction, that some buyer $b_{j}$ profits by choosing $\left(\hat{a}_{j}^{\prime} \neq a_{j}^{\prime}\left(r^{\prime}\right), \sigma_{j}^{\prime}\right)$ when the other buyers keep their strategies. Denote $\hat{a}^{\prime} \equiv\left(\hat{a}_{j}^{\prime}, a_{-j}^{\prime}\left(r^{\prime}\right)\right)$, 
$\sigma^{\prime} \equiv\left(\sigma_{j}^{\prime}, \sigma_{-j}\left(r^{\prime}\right)\right)$ and $y \equiv f\left(\hat{a}^{\prime}, r^{\prime}, \sigma^{\prime}\right)$. If $b_{j}=b_{1}$, then $b_{1}$ must obtain a true payoff greater than zero by selecting $\left(\hat{a}_{1}^{\prime}, \sigma_{1}^{\prime}\right)$. This implies that $b_{1}$ is not matched to $s_{3}$ at $y$ because $a_{13}=0$ and $b_{1}$ is not matched to $s_{4}$ at $y$ either because $a_{14}=1 / 2=r^{\prime} \leq$ $\Pi_{4}\left(\hat{a}^{\prime}, r^{\prime}\right)$, so $b_{1}$ would not have a positive true payoff. If $y_{11}=1$, the matching $x$ defined above is optimal for $M\left(\hat{a}^{\prime}, r^{\prime}\right)$. Then, $10-p_{2}\left(\hat{a}^{\prime}\right)=\hat{a}_{32}^{\prime}-p_{2}\left(\hat{a}^{\prime}\right) \leq \hat{a}_{33}^{\prime}-p_{3}\left(\hat{a}^{\prime}\right) \leq$ $\hat{a}_{33}^{\prime}=5$ by the competitiveness of $p\left(\hat{a}^{\prime}\right)$, and so $p_{2}\left(\hat{a}^{\prime}\right) \geq 5$. On the other hand, $x_{22}=1$, so $p_{2}\left(\hat{a}^{\prime}\right) \leq 5$. Then, $p_{2}\left(\hat{a}^{\prime}\right)=5$, so $\hat{a}_{21}^{\prime}-p_{1}\left(\hat{a}^{\prime}\right) \leq \hat{a}^{\prime}{ }_{22}-p_{2}\left(\hat{a}^{\prime}\right)=0$, and $p_{1}\left(\hat{a}^{\prime}\right) \geq \hat{a}_{21}^{\prime}=5$ by the competitiveness of $p\left(\hat{a}^{\prime}\right)$. Therefore, $\left.U_{1}\left(\Pi\left(\hat{a}^{\prime}, r^{\prime}\right), y, \sigma^{\prime}\left(r^{\prime}\right)\right)\right) \leq 0$. If $y_{12}=1$, then $y_{21}=y_{33}=1$ and, by arguing as before, we get that $p_{2}\left(\hat{a}^{\prime}\right) \geq 5$. Consequently, $U_{1}\left(\Pi\left(a^{\prime}\left(r^{\prime}\right), r^{\prime}\right), f\left(a^{\prime}\left(r^{\prime}\right), r^{\prime}, \sigma\left(r^{\prime}\right)\right)\right) \leq 0$. Hence, $b_{1}$ cannot profit by deviating from $\hat{a}_{1}^{\prime}$, so $b_{j} \neq b_{1}$. With analogous arguments we can see that $b_{2}$ cannot profit by deviating from $\hat{a}_{2}^{\prime}$. Therefore, $b_{j}=b_{3}$, and so $U_{3}\left(\Pi\left(a^{\prime}\left(r^{\prime}\right), r^{\prime}\right), f\left(a^{\prime}\left(r^{\prime}\right), r^{\prime}, \sigma\left(r^{\prime}\right)\right)\right)>5$. This implies that $b_{3}$ must be matched to $s_{2}$ because otherwise her true payoff would be less than or equal to 5 . In this case, the matching $x^{\prime}$ is optimal for $M\left(\hat{a}^{\prime}, r^{\prime}\right)$, so $u_{2}\left(\hat{a}^{\prime}\right)=0$ and $p_{3}\left(\hat{a}^{\prime}\right)=0$, and so $a_{22}^{\prime}\left(r^{\prime}\right)-p_{2}\left(\hat{a}^{\prime}\right) \leq u_{2}\left(\hat{a}^{\prime}\right)$ by the competitiveness of $p\left(\hat{a}^{\prime}\right)$. Then, $5-p_{2}\left(\hat{a}^{\prime}\right) \leq 0$, so $p_{2}\left(\hat{a}^{\prime}\right) \geq 5$, and $U_{3}\left(\Pi\left(a^{\prime}\left(r^{\prime}\right), r^{\prime}\right), f\left(a^{\prime}\left(r^{\prime}\right), r^{\prime}, \sigma\left(r^{\prime}\right)\right)\right) \leq 5$, which is a contradiction. Hence, no buyer can profit by deviating from her strategy and then $\left(a^{\prime}\left(r^{\prime}\right), \sigma\left(r^{\prime}\right)\right)$ is an NE for the buyers.

Now, we show that no seller $s_{k}$ has an incentive to deviate from $r^{\prime}{ }_{k}$. Suppose, by way of contradiction, that there is some $s_{k}$ who is better off by choosing $\hat{r}^{\prime}{ }_{k}$. Denote $\hat{r}^{\prime} \equiv\left(\hat{r}_{k}^{\prime}, r_{-k}^{\prime}\right)$, with ${\hat{r}^{\prime}}_{k}>0$ if $k \neq 4$ and ${\hat{r}^{\prime}}_{4} \neq 0.5$. Since $\left(a^{\prime}\left(\hat{r}^{\prime}\right), \sigma\left(\hat{r}^{\prime}\right)\right)$ is an NE and $\Pi \in \mathrm{C}^{+}$, Theorem 3 implies that $\left(\Pi\left(a^{\prime}\left(\hat{r}^{\prime}\right), \hat{r}^{\prime}\right), f\left(a^{\prime}\left(\hat{r}^{\prime}\right), \hat{r}^{\prime}, \sigma\left(\hat{r}^{\prime}\right)\right)\right) \in \mathrm{E}\left(a, \hat{r}^{\prime}\right)$. Clearly $s_{k} \neq$ $s_{1}$ (seller $s_{1}$ does not have any incentive to deviate because he receives the highest possible payoff). Suppose that $s_{k}=s_{2}$. To have $V_{2}\left(\Pi\left(a^{\prime}\left(\hat{r}^{\prime}\right), \hat{r}^{\prime}\right), f\left(a^{\prime}\left(\hat{r}^{\prime}\right), \hat{r}^{\prime}, \sigma\left(\hat{r}^{\prime}\right)\right)\right)>5$, $s_{2}$ should be matched to $b_{3}$ under $z \equiv f\left(a^{\prime}\left(\hat{r}^{\prime}\right), \hat{r}^{\prime}, \sigma\left(\hat{r}^{\prime}\right)\right)$, which is an optimal matching for $M\left(a, \hat{r}^{\prime}\right)$. In this case $s_{3}$ cannot be matched to $b_{3}$, so $\Pi_{3}\left(a^{\prime}\left(\hat{r}^{\prime}\right), \hat{r}^{\prime}\right)=0$. Therefore, because $\left(\Pi\left(a^{\prime}\left(\hat{r}^{\prime}\right), z\right)\right.$ is competitive in $M\left(a, \hat{r}^{\prime}\right), a_{32}-\Pi_{2}\left(a^{\prime}\left(\hat{r}^{\prime}\right), \hat{r}^{\prime}\right) \geq a_{33}-\Pi_{3}\left(a^{\prime}\left(\hat{r}^{\prime}\right), \hat{r}^{\prime}\right)$ $=5$, from which follows that $\Pi_{2}\left(a^{\prime}\left(\hat{r}^{\prime}\right), \hat{r}^{\prime}\right) \leq 10-5=5$. Then, $V_{2}\left(\Pi\left(a^{\prime}\left(\hat{r}^{\prime}\right), \hat{r}^{\prime}\right), f\left(a^{\prime}\left(\hat{r}^{\prime}\right)\right.\right.$, $\left.\left.\hat{r}^{\prime}, \sigma\left(\hat{r}^{\prime}\right)\right)\right)=\Pi_{2}\left(a^{\prime}\left(\hat{r}^{\prime}\right), \hat{r}^{\prime}\right)-r_{2} \leq 5$, which is a contradiction. If $s_{k}=s_{3}, s_{3}$ is not acceptable for $b_{1}$ and $b_{2}$ in $M\left(a^{\prime}\left(\hat{r}^{\prime}\right), \hat{r}^{\prime}\right)$, since $a_{13}=a_{23}=0<\hat{r}_{3}^{\prime}$. Thus, in order to have $V_{3}\left(\Pi\left(a^{\prime}\left(\hat{r}^{\prime}\right), \hat{r}^{\prime}\right), f\left(a^{\prime}\left(\hat{r}^{\prime}\right), \hat{r}^{\prime}, \sigma\left(\hat{r}^{\prime}\right)\right)\right)>0, s_{3}$ should be matched to $b_{3}$ at $f\left(a^{\prime}\left(\hat{r}^{\prime}\right), \hat{r}^{\prime}\right.$, $\left.\sigma\left(\hat{r}^{\prime}\right)\right)$, which is an optimal matching for $M\left(a, \hat{r}^{\prime}\right)$. The value of $f\left(a^{\prime}\left(\hat{r}^{\prime}\right), \hat{r}^{\prime}, \sigma\left(\hat{r}^{\prime}\right)\right)$ in 
$M\left(a, \hat{r}^{\prime}\right)$ is $15-\hat{r}_{3}^{\prime}$. However, the value of the matching $z^{\prime}$ in $M\left(a, \hat{r}^{\prime}\right)$, where $z^{\prime}{ }_{11}=$ $z_{32}^{\prime}=1$, is $\underline{a}_{11}\left(\hat{r}^{\prime}\right)+\underline{a}_{32}\left(\hat{r}^{\prime}\right)=15>15-\hat{r}_{3}^{\prime}$, which contradicts the optimality of $f\left(a^{\prime}\left(\hat{r}^{\prime}\right), \hat{r}^{\prime}, \sigma\left(\hat{r}^{\prime}\right)\right)$. Hence, $s_{3}$ cannot profit by deviating from $\hat{r}^{\prime}{ }_{3}$. It remains to verify the case $s_{k}=s_{4}$. In order to have $V_{4}\left(\Pi\left(a^{\prime}\left(\hat{r}^{\prime}\right), \hat{r}^{\prime}\right), f\left(a^{\prime}\left(\hat{r}^{\prime}\right), \hat{r}^{\prime}, \sigma\left(\hat{r}^{\prime}\right)\right)>0, s_{4}\right.$ should be matched to some buyer at $f\left(a^{\prime}\left(\hat{r}^{\prime}\right), \hat{r}^{\prime}, \sigma\left(\hat{r}^{\prime}\right)\right)$, which is not possible because $s_{4}$ is unmatched at any optimal matching for $M\left(a, \hat{r}^{\prime}\right)$. Hence, $\left(r^{\prime}, a^{\prime}(),. \sigma().\right)$ is an SPE of $\Gamma(a, r, \Pi, f)$.

It is a matter of verification that $p_{*}(r)=(0,5,0,0.5)$. Therefore, this example also illustrates that $M(a, r)$ may have more than one competitive equilibrium.

\section{CONCLUSION}

We have analyzed the SPE of centralized mechanisms for the buyer-seller game. In any such mechanism, each seller is asked to report the valuation of his object and then buyers are requested to report their valuations for all the objects (together with a signal to break ties). Given the reports, a competitive price rule selects a competitive equilibrium vector of prices (for the reported market) and a competitive matching rule provides a competitive equilibrium matching.

At equilibrium, buyers and/or sellers often have an incentive not to report their valuations truthfully, as we know from previous literature. Still, we have shown that the SPE strategies typically lead to outcomes that are not only competitive equilibria for the reported economy but also for the true economy. While buyers' SPE strategies may lead to the minimum competitive equilibrium prices, sellers profit from the first-mover advantage and, under reasonable conditions, all the SPE outcomes select the maximum competitive equilibrium prices for the true economy.

\section{REFERENCES}

Alcalde J., D. Pérez-Castrillo and A. Romero-Medina (1998): "Hiring procedures to implement stable allocations," Journal of Economic Theory 82, 469-480.

Budish, E. (2011): "The combinatorial assignment problem: Approximate competitive equilibrium from equal incomes," Journal of Political Economy 119, 1061-1103.

Demange, G. (1982): "Strategyproofness in the assignment market game," Preprint. Paris: École Polytechnique, Laboratoire d'Économetrie.

Demange, G. and D. Gale (1985): "The strategy structure of two-sided matching 
markets," Econometrica 55, 873-88.

Gale, D. (1960): “The theory of linear economic models," New York: McGraw Hill.

Hayashi, T. and T. Sakai (2009): "Nash implementation of competitive equilibria in the job-matching market," International Journal of Game Theory 38, 453-467.

Jaramillo, P., C. Kayi and F. Klijn (2013): "Equilibria under deferred acceptance: Dropping strategies, filled positions, and welfare," Games and Economic Behavior 82, 693-701.

Kamecke, U. (1989): "Non-cooperative matching games," International Journal of Game Theory 18, 423-431.

Kelso, A. and V.P. Crawford (1982): "Job matching, coalition formation, and gross substitutes," Econometrica 50, 1483-1504.

Kojima, F. and P.A. Pathak (2009): "Incentives and stability in large two-sided matching markets," American Economic Review 99, 608-627.

Leonard, H.B. (1983): "Elicitation of honest preferences for the assignment of individuals to positions," Journal of Political Economy 91, 461-479.

Ma, J. (2010): "The singleton core in the hospital-admissions problem and its application to the National Resident Matching Program (NRMP)," Games and Economic Behavior 69,150-164.

Pérez-Castrillo, D. and M. Sotomayor (2002): "A simple selling and buying procedure," Journal of Economic Theory 103, 461-474.

Pérez-Castrillo, D. and M. Sotomayor (2013): "On the manipulability of competitive equilibrium rules in many-to-many buyer-seller markets," working paper BGSE.

Roth, A. (1985): "The college admissions problem is not equivalent to the marriage problem," Journal of Economic Theory 36, 277-288.

Roth A. and M. Sotomayor (1990): "Two-sided matching. A study in game-theoretic modeling and analysis," Econometric Society Monograph Series, N. 18 Cambridge University Press.

Shapley, L. and M. Shubik (1972): “The assignment game I: The core," International Journal of Game Theory 1, 111-130. 
Sotomayor, M. (1986): "On incentives in a two-sided matching market," Department of Mathematics, Pontificia Universidade Católica do Rio de Janeiro.

Sotomayor, M. (2000): "Existence of stable outcomes and the lattice property for a unified matching market," Mathematical Social Science 39, 119-132.

Sotomayor, M. (2002): “A simultaneous descending bid auction for multiple items and unitary demand", Revista Brasileira de Economia, 56, n. 3, 497-510.

Sotomayor, M. (2007): “Connecting the cooperative and competitive structures of the multiple-partners assignment game," Journal of Economic Theory 134, 155-74.

Sotomayor, M. (2008): "Admission games induced by stable matching rules," International Journal of Game Theory 36 (34), 621-640.

Sotomayor, M. (2012): “A further note on the college admission game," International Journal of Game Theory 41, 179-193. 